\title{
AN EVALUATION OF TRAFFIC SIGNAL COORDINATION
}

\section{SEPTEMBER 1971 - NUMBER 17}

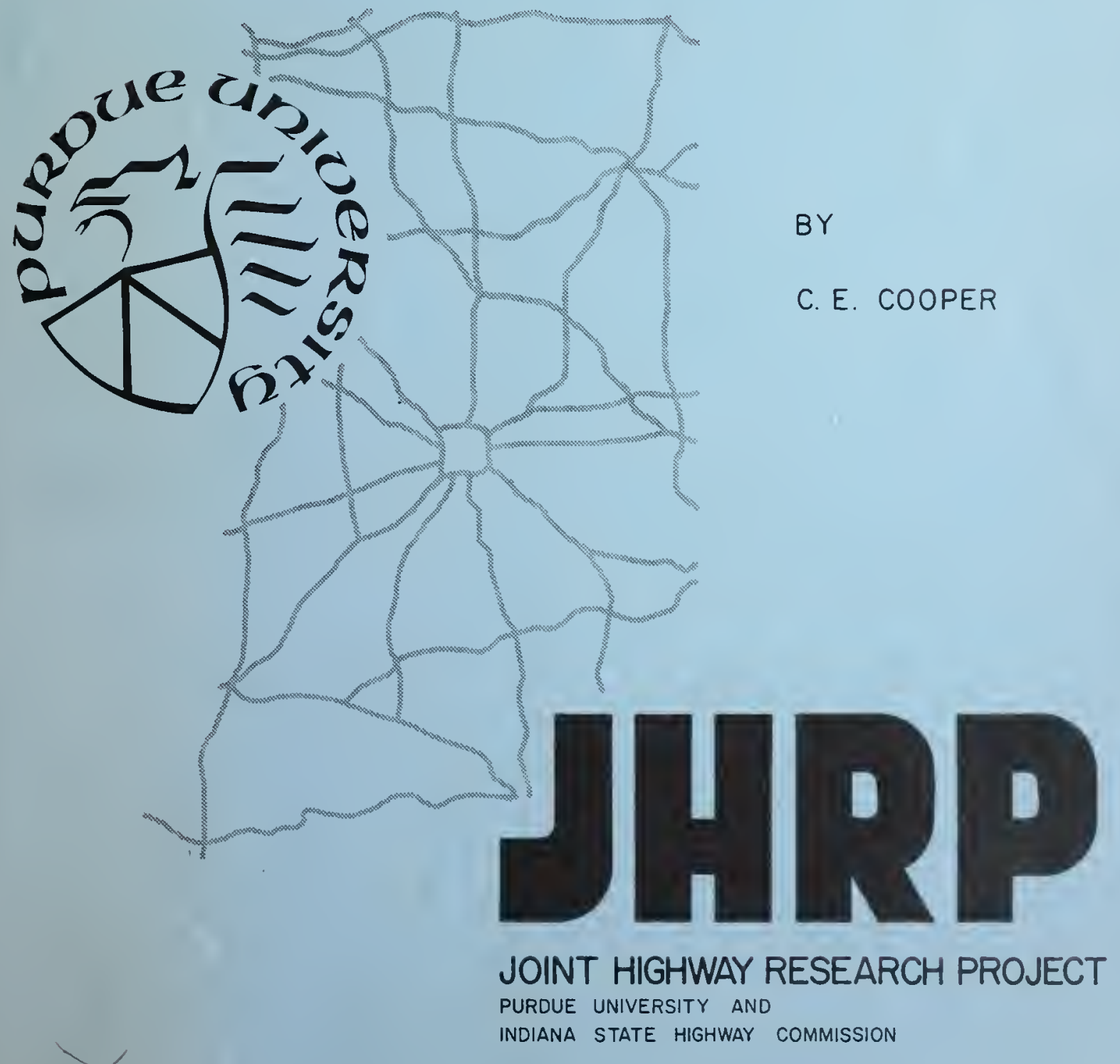





\section{Final Report}

\section{AN EVALUATION OF TRAFFIC SIGNAL COORDINATION}

TO: J. F. McLaughlin, Director

Joint Highway Research Project

FROM: H. L. Michael, Associate Director Joint Highway Research Project
September 28,1971

Project: C-36-17AA

File: $\quad 8-4-27$

The attached Final Report titled "An Evaluation of Traffic Signal Coordination" is on a project approved by the Advisory Board on January 30,1963 . The original research and subsequent research since that time have been completed by the author, $\mathrm{Mr}$. Conway Cooper, a Graduate Assistant in Research on our staff, under the direction of Professor W. L. Grecco.

The research is an evaluation of the effectivness of a flexible coordinated traffic signal system relative to traffic flow. The system studied is the one installed in 1962 in the Lafayette, Indiana CBD area. Considerable reduction in delay time and operating costs resulted from installation of the system studied. These benefits when converted to dollar value were sufficient to pay for the costs of the system in less than two years.

The report is submitted to the Board for acceptance as fulfillment of the objectives of the project.

Respectfully submitted,

HLM : ms

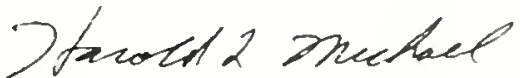

Harold L. Michael

Associate Director
CC: F. L. Ashbaucher

W. L. Dolch

W. H. Goetz

W. L. Grecco

M. J. Gutzwiller

G. K. Hallock
M. E. Harr

R. H. Harrell

M. L. Hayes

R. D. Miles

J. W. Miller

C. F. Scholer
M. B. Scott

W. T. Spencer

J. A. Spooner

N. W. Steinkamp

H. R. J. Walsh

K. B. Woods

E. J. Yoder 
Final Report

AN EVALUATION OF TRAFFIC SIGNAL COORDINATION

\author{
by \\ Conway E. Cooper \\ Graduate Assistant in Research \\ Joint Highway Research Project \\ Project No.: C-36-17AA \\ File No.: 8-4-27 \\ Conducted By \\ Joint Highway Research Project \\ Engineering Experiment Station \\ Purdue University \\ In Cooperation with \\ Indiana State Highway Commission
}

Purdue University

Lafayette, Indiana

September 28, 1971 
Digitized by the Internet Archive in 2011 with funding from

LYRASIS members and Sloan Foundation; Indiana Department of Transportation 


\section{ACKNOWLEDGMENTS}

The author wishes to express his sincere appreciation to his advisor, Professor William L. Grecco, for his guidance and advice throughout this study and for his critical review of the manuscript; to the other committee members, Professor Harold L. Michael, for his critical review of the manuscript, and Professor Virgil L. Anderson, for his assistance in the statistical analysis and his review of the manuscript; to Mr. George Stafford for his valuable aid in the data collection; and to my wife, Frances, for her encouragement and for typing the manuscript.

The author is very grateful and wishes to extend his thanks to the Joint Highway Research Project of Purdue University and the Indiana State Highway Commission for making this study possible through their financial support .

The cooperation of Mr. James Coomey and the men of the Lafayette Traffic Improvement Department is also greatly appreciated.

A special thanks is extended to those responsible for the special consideration given the author due to his lengthy illness during the latter stages of the project.

Finally the author wishes to thank God for the strength and sound mind required to complete this work. 
TABLE OF CONTENTS

Page

LIST OF TABLES. . . . . . . . . . . . . . . . . . . . . vi

LIST OF FIGURES . . . . . . . . . . . . . . . . . . . . vii

ABSTRACT. . . . . . . . . . . . . . . . . . . ix

INTRODUCTION. . . . . . . . . . . . . . . . . . . . 1

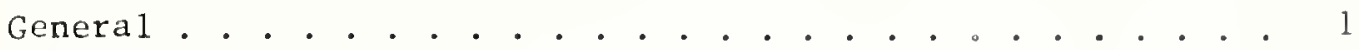

Purpose . . . . . . . . . . . . . . . . . . 3

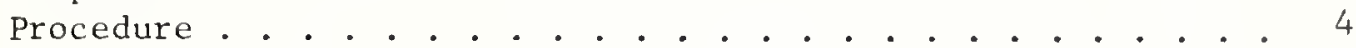

REVIEW OF LITERATURE. . . . . . . . . . . . . . . . . . . 5

Travel Time and Delay . . . . . . . . . . . . 5

An Economic Consideration . . . . . . . . . . . . . 7

Related Studies........... . . . . . . . . . 8

A New Approach. . . . . . . . . . . . . . . . 10

STUDY AREA AND TRAFFIC SIGNAL SYSTEMS . . . . . . . . . . . 12

Study Area. . . . . . . . . . . . . . . . . . 12

Traffic Signal Systems. . . . . . . . . . . . . . 19

DATA COLLECTION . . . . . . . . . . . . . . . . . 32

DATA REDUCTION. . . . . . . . . . . . . . . . . 41

Volume Data... . . . . . . . . . . . . . 4 41

Travel Time Data................ . . 42

ANALYSIS OF DATA. . . . . . . . . . . . . . . . . . 47

Analysis of Variance. . . . . . . . . . . . . . . 47

Economic Analysis . . . . . . . . . . . . . . 60

RESULTS AND CONCLUSIONS . . . . . . . . . . . . . . . . 70 
SUGGESTIONS FOR IMPROVEMENT AND ADDITIONAL RESEARCH . . . . . . 75

Suggestions for Improving the Flexible System 。. . . . 75

Suggestions for Additional Research . . . . . . . . . 80

BIBLIOGRAPHY. . . . . . . . . . . . . . . . . . . 82

\section{APPENDICES}

Appendix A: Sample Calculations for the Annual Operating and Delay Costs to the Road-Users for a Given Route and Mode of Operation . . . . . . . . . . . . . . . . . 84 Appendix B: Table 16. Average Running Speeds for Different Modes and Routes. . . . . . . . . . . . . . . 87 
LIST OF TABLES

Table

Page

1. Samples Needed for Determining Mean Over-All speeds on Selected Test Sections within Different Limits for 95 Percent Degree of Confidence. . . . . . . . . . 36

2. Number of Observations Per Cell for Final Sample Size . . 49

3. Results of Bartlett's Test for Homogeneity of Variances. 51

4. Results of the Analysis of Variance for Total Travel Time........................ 53

5. Results of the Analysis of Variance for Delay Time.... . 54

6. Results of the Analysis of Variance for Running Time. . . 55

7. Results of the Analysis of Variance for Number of Stops Per Run . . . ................... 56

8. Results of Analysis of Variance for Time Per Stop.... . 57

9. Results of Scheffé Test for Differences in Means..... . 61

10. Over-All Means Obtained from the Statistical Analysis... 63

11. Values Used for Computing Operating and Delay Costs . . . 65

12. Average Daily Volumes for the Time Period from 7:00 A.M. to 7:00 P.M. ................... 67

13. Annual Cost to the Users for Different Signal Systems。。. 68

14. 1963 Present Worth of Savings Attributable to the Flexible Traffic Signal System . . . . . . . . . . . . 69

15. Stop Sumarization for Locations with High Incidence of Short Term Delays for the Flexible Mode of Operation.。.

Appendix

Table

16. Average Running Speeds for Different Modes and Routes . . 87 


\section{LIST OF FIGURES}

Figure

Page

1。 Indiana County Map。. . . . . . 。 . . 。 . . 。 13

2. Location of the C.B.D. in the Urban Area. . . . . . . . . 14

3. Map of the Lafayette Business District Showing the Limits of the Study Area, the Locations of Signalized Intersections, and the Direction of Traffic Flow on the Major

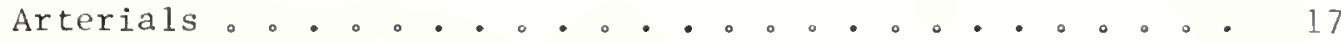

4. Columbia Street Hourly Volumes for Average Weekday. . . . 18

5. Main Street Hourly Volumes for Average Weekday. . . . . . 20

6. Third Street Hourly Volumes for Average Weekday - 1970. • . 21

7. Fourth Street Hourly Volumes for Average Weekday - 1970 . . 22

8. Elements of PR Coordinated Traffic Signal Control System. . 25

9. Map of the Lafayette Business District Showing the Locations of Vehicle Detectors and the Master Control Center for the Flexible Mode of Operation. . . . . . . . . . 29

10. Master Controller . . . . . . . . . . . 30

11. Map of Lafayette Business District Showing the Travel Time Routes, Volume Count Locations, and Spot Speed Locations. 。 34

12. Travel Time and Distance Recorder . . . . . . . . 37

13. Sample Section of Travel Time-Distance Recorder Tape. . . 39

14. Event Code................... . . 4 40

15. Map of Lafayette Business District Showing the Sections of the Travel Time Routes Used in the Analysis. . . . . . . 46

16. Columbia Street Regression of Travel Time on Volume Using Cell Means..................... 
17. Main Street Regression of Travel Time on Volume Using Cell Means . . . . . . . . . . . . . . . .

18. 1963 Present Worth of Savings Accumulated by the Flexible Traffic Signal System Using Interest Rate of Ten Percent. 
ABSTRACT

Cooper, Conway Edward, MSCE, Purdue University, August 1971. An Evaluation of Traffic Signal Coordination. Major Professor: William L. Grecco.

This research reports the results of a study to determine the impact of a flexible coordinated traffic signal system on the traffic patterns and flow of a medium sized city. The primary objective of the research was to evaluate the benefits realized by the installation of a flexible coordinated system when compared to less sophisticated and less costly systems, then to determine whether or not the benefits derived justified the cost of the flexible system.

The project was started in the fall of 1962 at which time the city of Lafayette, Indiana, in cooperation with the Indiana State Highway Commission had contracted to have a flexible coordinated traffic control system installed in the central business district of the city. This system utilizes Electro-Matic PR Coordinated Signal Control System equipment manufactured by the Automatic Signal Division of Laboratory for Electronics, Inc. This installation afforded a great opportunity to obtain the data required to evaluate the impact and economic consequences of a system of this type on a medium sized city.

At this time travel time runs, with simultaneous volumes taken, were conducted for three different modes of signal operation, these being an uncoordinated random mode, a coordinated simultaneous mode, and a 
coordinated single alternate mode. When work resumed in 1970 travel time runs were conducted for the flexible coordinated system, and the analysis was performed.

In order to isolate the effect of the signal timing on delays, runs involving other delays due to pedestrians, turning cars, and parking cars were discarded. This allowed the relationships among volume, travel time, and signal mode to be determined.

The analysis was intended to reveal which system functioned most efficiently at different volume levels; however, the flexible system was shown to be superior to the other modes over the entire range of volumes tested. The flexible system produced significant savings in total travel times, delay times, and number of stops per run for all volumes. An economic equation was developed, and the flexible system was shown to realize a savings in delay time and operating costs valued at the present time of approximately 140,000 dollars per year. Using a ten percent rate of return this analysis also showed the flexible system to have saved in terms of delay time and operating costs an amount equal to the initial capital cost of the system in less than two years from the completion of its installation. This analysis also showed the flexible system to have realized a net savings of 590,000 dollars for the period of time starting in 1963 and ending in 1971. A relatively high interest rate was used in order to compensate for the effects of inflation. Finally suggestions for improving the efficiency of the flexible system are given. 


\section{INTRODUCT ION}

\section{General}

Considerable research in the field of traffic operations has been conducted during recent years. However, much of the work has been concerned with either rural operations or the problems of large metropolitan areas, with relatively little research devoted to the needs of the small to medium sized cities. These communities are often faced with traffic problems as real and complex as those existing in the large cities.

It is often said that the most important traffic problems to an individual are those problems encountered daily by that individual. As a natural consequence of this maxim, curbstone traffic engineers sometimes propose "solutions" that are logical to them but unrealistic. The small city, lacking trained personnel with adequate factual information, is particularly vulnerable to community and political pressures resulting from these proposals. Often officials are forced into action by these pressures, and in many instances the results are less than desirable.

In recent years the flexible coordinated traffic signal system has been acclaimed as the ultimate in moving traffic efficiently. This is the signal system with a brain; no longer is the traffic engineer tied to a pre-timed three dial local controller. He can now have the system in effect that meets the instantaneous demand most efficiently through vehicle detection, computerization and interconnection. This is good, 
but can this system be used effectively and economically in the small to medium sized city? Do the demands vary enough in the small city to warrant the flexibility of this new system? Do the benefits derived justify the additional expense of the flexible system? Would a less expensive system get the job done at the same efficiency? These are questions that must be answered before the policy makers can make a reasonable decision.

Pre-timed coordinated systems are very efficient in some instances. These systems do not have the ability to respond to the actual traffic demand, but operate within a pre-determined set of cycle lengths (usually three) based upon average conditions. Pre-timed systems are less sophisticated than flexible systems; therefore, require less equipment and are less costly. Perhaps this system is the answer to the small city traffic dil emma.

Coordination is provided by interconnecting circuits of individual intersection controllers so as to cause traffic to move in platoon fashion. Under normal traffic volumes, properly coordinated signals can be very effective in producing a smooth flow of traffic. However, coordinated movements are often shattered if the street is overloaded. Four systems of coordination are in common use. They utilize simultaneous, alternate, simple progressive, and flexible progressive modes of operation. Here the first three modes refer to pre-timed systems and in the case of the fourth mode the word flexible refers to its ability to monitor actual traffic conditions. The flexible system could be programmed to produce any of the three previous modes of operation at predetermined levels of vehicle detection. The simultaneous mode makes all color indications 
on a given street alike at the same time, and produces high vehicle speeds between stops but low overall speeds. The alternate mode has all signals (single alternate) or adjacent pairs of signals (double alternate) on a given street show different colors. Alternating operation requires that the cycle be divided so that the minor street receives the same percentage of green time at all intersections; this is also true with simultaneous operation. The simple progressive system provides indications at each intersection individually so that traffic moves in a nearly continuous flow of platoons at a predetermined speed. While requiring a common cycle length, it does permit some variation in the cycle divisions. The flexible progressive system uses a mastercontroller device that directs the local intersection controllers. This provides more flexibility by permitting remote control adjustments of the cycle length, offsets, and splits.

As the signal system becomes more sophisticated, it also becomes more complex. The result is greater cost. Because of their participation in the costs, public works agencies are concerned with the value received for the funds invested. Therefore, it is necessary to evaluate the effects of a flexible coordinated system on the traffic flow of a medium sized city so that we might have factual information on which to base the feasibility of installing this system in cities of like population.

\section{Purpose}

The purpose of this study is to investigate the interrelationships among travel time, delay time, congestion, and signal coordination on one-way streets in the central business district (CBD) of Lafayette, 
Indiana. The comparison of these data with the associated costs to the road-user permits an evaluation of the effectiveness of the different types of signal operation. This analysis reveals the overall effectiveness of the flexible coordinated system relative to less costly alternatives.

\section{Procedure}

Factual information is best obtained by before and after studies of traffic patterns. Such studies can only be accomplished by the actual installation of a coordinated signal system. The installation in Lafayette provided an excellent opportunity to obtain this evaluation. The flexible coordinated system was to be compared with less costly coordinated and uncoordinated pre-timed systems. A good indicator of a system's relative value is reflected in the time required to traverse a given route through the system under varying conditions of volume. If travel time data is collected for each mode of operation for the same route and the same volumes certain conclusions as to the relative worth of each system under all conditions can be drawn. Travel time runs were conducted under the same conditions for each of these four modes of signal operation:

1. Uncoordinated random signal settings

2. Coordinated simultaneous signal settings

3. Coordinated single alternate signal settings

4. Flexible coordinated signal settings

An analysis will be performed using this data to determine which of these systems operates most efficiently at different volume levels. Finally benefits realized by the flexible system in monetary terms will be determined. 
REVIEW OF LITERATURE

This study deals most heavily with the economic evaluation of alternative methods of controlling urban traffic. In order to obtain the information required for this evaluation the two closely related subjects of travel time and delay become topics of interest also. An investigation of the literature related to these three subjects reveals a preponderance of material available concerning travel times and delays. Since the interest here is not to develop a new method of collecting this type of data or development of an alternative measure of a system's effectiveness, the review pertaining to these subjects will serve only to illustrate the various methods employed in obtaining travel times and delays.

\section{Travel Time and Delay}

Total travel time is the time required for a vehicle to traverse a given section of roadway. Included are stopped time and running time. Running time is the time that the vehicle is in motion and stopped time, as it implies, is the time the vehicle is required to be stopped due to traffic control devices and other factors that tend to impede the flow of traffic. Because the driver often considers total travel time in reaching his destination as the criterion for selecting a certain route, travel time is given consideration in the evaluation of a highway system ( 1$)^{*}$.

\footnotetext{
* Numbers in parentheses refer to items in Bibliography.
} 
Travel time is an effective measure of level of service, both for individual routes and for urban streets and freeway systems (2)。As in this research, one of the objectives of travel time studies is analyzing roaduser benefits (3).

Travel times and delays can be measured by any of several different methods. The information that is to be obtained sometimes dictates the method to be used. Such was the case in this study. Generally travel time data is collected by either license matching procedures or test car techniques.

The license matching method has been generally accepted as being a reliable standard upon which to base the accuracy of other methods. License numbers along with the time of the observation are recorded at the terminal points of the test section. The numbers are later matched to determine the travel time. The major disadvantages of this method are the large number of man-hours required for matching and the fact that delays are not identified according to location and cause. A variation of this method is the arrival-output volume rate method. This method is useful only where there is reasonable certainty that vehicles will pass both observation points of the test section (4).

There are two generally acceptable test car methods ("average car" method and "floating car" method)。According to the "floating car" method the driver of the test vehicle is instructed to pass as many cars as pass him, and in the "average car" method the driver is to approximate the average speed of the traffic without maintaining a balance of passings. The "average car" method has been found to produce results with higher accuracy than the "floating car" method for the same sample size $(4,5)$. 
Another test car technique is known as the "maximum car" method by which the driver is instructed to maintain a speed as near as possible to the maximum allowable speed limit. This method is not thought to give a true measure of average travel times (3).

Other less used methods include spot speeds (not accurate unless the speed over the entire test section is nearly uniform), ground or air photography, and driver interviews (4).

For a more complete review of the literature dealing with trave 1 times and delays see reference 6 .

\section{An Economic Consideration}

Included in the annual cost of highways are first cost, maintenance cost, operating cost, administrative and overhead cost, resurfacing cost, salvage value and the rate of return (7). These are the costs that are dealt with when different projects are compared with respect to benefits in order to determine which alternative is most desirable. However, the major portion of the annual cost associated with the operation of an urban traffic signal system is the cost to the user (operating cost).

The evaluation of highway user costs is an important step in the economic analysis of highway improvements (8). This statement also pertains to urban streets and traffic control systems. The performance of vehicles has been observed and the results reported, beginning in 1920 . Winfrey (9) states:

"Despite the years of research and testing of the performance of motor vehicles, the literature is still seriously lacking in the effect of highway design and traffic operations on the running cost of motor vehicles. With the increase in traffic and the development of urban congestion, it has become desirable to study minutely the features of highway design as they affect the running cost of motor vehicles." 
Several methods have been developed to determine vehicle operating costs. Among these are individual vehicle owner records, laboratory tests, and actual vehicle testing. In general these methods have been used independently of one another, however, better results could be obtained by combinations of these methods. Winfrey feels that an accurate measure of the following cost related items is needed in the calculation of vehicle operating costs: a) fuel consumption, b) tire tread wear, c) engine oil consumption, d) maintenance and repair, e) depreciation expense, and f) accident costs. He concludes that:

"Concentrated study of the literature on the running cost of motor vehicles as related to highway design and traffic operations reveals the fact that much yet remains to be done through testing of vehicles to produce the desirable results."

\section{Related Studies}

Very little research has been done comparing the effects of different signal systems utilizing different modes of operation within the same arterial street system. Generally work done in this area attempts to develop practical methods for evaluating the performance of classes of street and signal systems so that a workable plan for comparing different sections of similar geometrics and signalization might be made available. In a study by J. Fo Torres (10) travel time was shown to be the key factor in the evaluation of traffic operations and was also shown to be significantly and reliably related to volume, given specific street section characteristics. of the variables tested signal density was shown to have the most significant effect on the variation of travel times in coordinated systems. Road width, percent green time, and parking had a lesser effect. The signal density weighted by the ADT of the 
cross traffic was found to be the significant factor for trafficactuated and traffic-supervised systems.

The procedures and results of the following two evaluation type studies are thought to be pertinent to this research. The first, a study comparing a random signal system, a progressive signal system, and the pacer system (11) was started in 1961 in Macomb County, Michigan and ran for a period of 15 months. The pacer system was developed in 1954 in Germany by Dr. Wolfgang von Stein. This system not only incorporates accurate phasing of successive intersection signals, but also provides continuous supplementary speed information for arrivals during the green phase of the cycle. This is accomplished through staging areas on the signal system approaches that regulate traffic speed to the speed of progression through pre-signals and variable speed displays that indicate the optimum speed for clearing all signals. This study showed decreased number of stops and increased intersection capacity attributed to the pacer system. Also this system was shown to be favored by the majority of motorists. The second study (12), conducted in Washington, D.C., was to determine the changes in traffic flow characteristics measured on a system of three parallel streets, when the operation of the system was changed from three two-way streets to a one-way street on cach side of a two-way street. Here the results are not as pertinent as the procedure used in the economic analysis. A monetary value was to be placed upon the savings realized by the change in traffic operations. To obtain this the mean travel time for each condition was multiplied by the respective daily volumes. This resulted in a total daily travel time. The total for the new operation was subtracted from the old and the result 
was multiplied by 1.35 dollars per hour (value of time) to obtain a daily savings. The cost savings for the stops eliminated by the new system operation was also determined. These figures were then expanded to a yearly savings.

\section{A New Approach}

Traffic engineers see the need to upgrade our signal systems to better meet today's demands. J. L。 Kay (13) puts it this way:

"The problems of urbanization have manifested themselves in many ways. One of the more publicized elements-traffic congestion--is of immediate concern to the traffic engineer. In an attempt to reduce the congestion, every effort is being made to maximize the service offered to the motorists by the surface street system. That part of the overall system which controls traffic through major intersections--traffic signals--is being evaluated in many cities to determine which improvements are practical.

The signal control systems in many of these cities are over twenty years old. The control philosophies in use are constrained by the old equipment which was designed to meet the needs of the immediate post-World War II period. This equipment and its associated control philosophy may not be adequate to meet today's needs or those of the near future. A decision must be made as to what kind of revised control system is best suited to a given set of conditions. Since the decision involves a major investment, it should be made on as sound a basis as possible.

Traditionally, signal system evaluation has been based solely on the reduction in motorists' stops and delays. That approach assumes that reduction in stops and delays can be accurately forecast for a range of alternative systems over a long period of time. The precision of these forecasts is readily accepted when, in fact, the accuracy of such forecasting is questionable. In addition, it contains the inherent assumption that reduction in stops and delays is the only beneficial factor meriting consideration."

Kay feels that a new approach to signal system evaluations is needed since many benefits of a signal system are relatively intangible and 
cannot be translated accurately to a dollar benefit. He says it is necessary to develop a proxy value to measure system benefit or "utility". Then a composite value expressing each system's total utility could be developed. A systematic procedure for this new approach is given in his paper, and follows. Step one is definition of the goals of the signal system. This is followed by goal weighting in order to determine the proper relationships among the goals. The next step is to develop utility measures which further define each goal and to which a qualitative rating of each system can be applied. The systems are then ranked according to how well they meet each utility measure and a total utility value is calculated for each system. Finally a utility/cost comparison is done to determine which of the systems represents the most desirable investment. This is not as precise as the dollar technique benefit system, but it is more realistic since it considers goals other than just economic in the decision process.

New methods are being developed and employed in the areas of signal timing and system evaluations, among these are methods utilizing the electronic computer. Signal system information for given conditions is fed into the computer. Using the input data the computer is directed to simulate the system under different plans of operation, thus finding the optimum plan $(14,15)$. This technique could be very useful in the area of system evaluation, however little work has been done relating simulated results to actual results. 


\section{STUDY AREA AND TRAFFIC SIGNAL SYSTEMS}

\section{Study Area}

Lafayette is located in the west central part of the state of Indiana in Tippecanoe County (Figure 1). It is situated along the east bank of the Wabash River with the city of West Lafayette and Purdue University on the opposite bank of the river (Figure 2). According to the 1970 census the population of Lafayette was about 45,000. West Lafayette claimed approximately 20,000 residents, and Purdue enrolls about 27,000 students at this campus during the fall and spring semesters. The county population is over 108,000 .

Since the CBD of Lafayette is the only large commercial district in the county it is the focal point of the entire area; therefore, as could be expected Lafayette is faced with a very real traffic problem. This is not a problem that is unique to Lafayette since most cities of this size experience periods of congestion and delay daily; however, there are factors that tend to multiply the congestion in this area.

As previously stated the Wabash River cuts through this area separating Lafayette from West Lafayette and Purdue University. Only three river crossings are provided to serve the needs of the two cities, and all three are located in close proximity to the CBD (Figure 2). The result is that all inter-city traffic must cross the river at one of these three locations. This tends to "dump" a majority of the region's traffic in the 


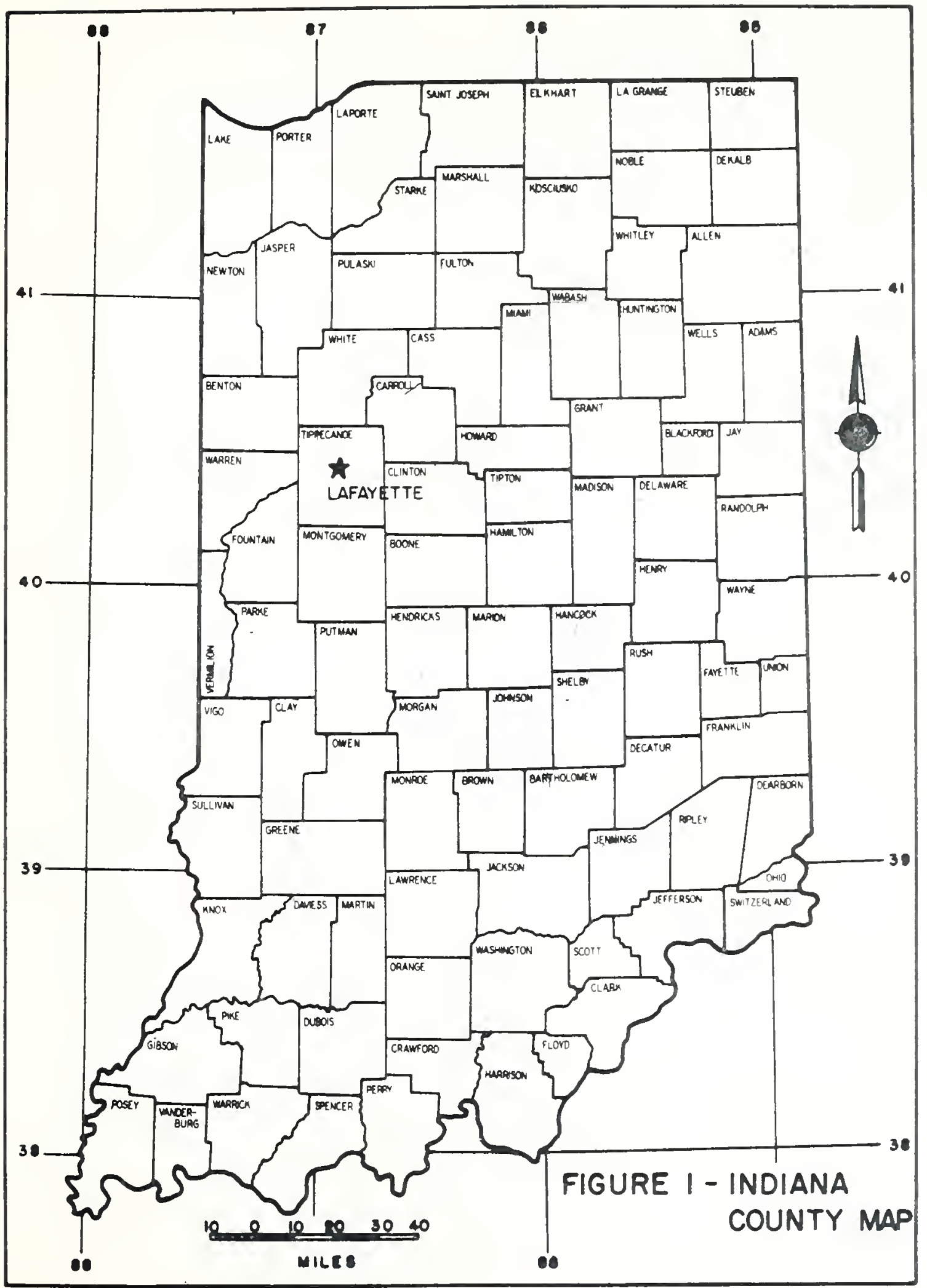




\section{LAFAYETTE Ind WEST LAFAYETTE} INOIANA

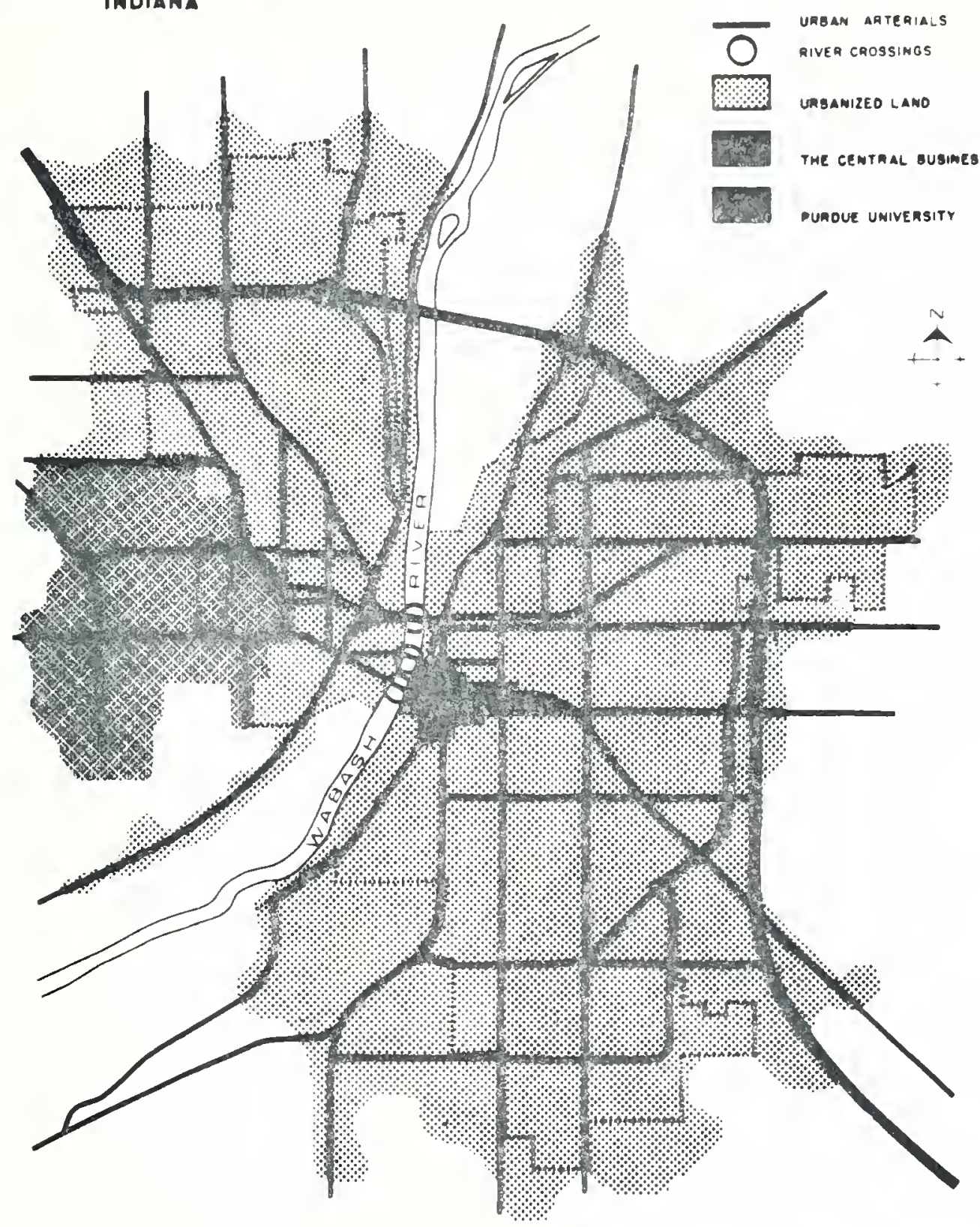

FIGURE 2 - LOCATION OF THE C.B.D. IN THE URBAN AREA 
Lafayette CBD. Many of the residents of the area reside in one city and work in the other. Work trips combined with the normal traffic and through traffic traversing the area by way of several state or federal routes which pass through the $\mathrm{CBD}$, create a great deal of congestion at peak times. The CBD arterial streets are taxed to and sometimes beyond capacity causing travel times and delays to mount. Because of this, the peaks are quite high and demands on the street system vary quite extensively in the course of one day. Another factor that tends to increase congestion is the presence of very short blocks in the CBD. This part of the city was developed during the nineteenth century when establishment of blocks of short length (approximately 340 feet in this case) was common practice. Congestion is intensified during peak times when traffic at cross streets is blocked by excessively long queues.

The major arterials in this area are shown in Figure 2. The eastwest arterials are two one-way couplets; Main and Columbia Streets which pass through the heart of the CBD and Union and Salem Streets which lie on its fringe. Signal operation on Union and Salem Streets is not effected by the new installation. The study area was naturally limited by the extent of the new system; therefore, Main and Columbia Streets were the obvious choice on which to conduct the travel time runs. The study area includes the $\mathrm{CBD}$ and its fringe area encompassing a total of 30 signalized intersections, 14 being city owned and 16 on state roads, therefore stated owned (Figure 3).

Columbia street carries eastbound traffic through the CBD at an average weekday rate of 6,730 vehicles per 12 hour day (7:00 A.M. to 7:00 P.M.) (Figure 4). Main Street serves westbound traffic for the 


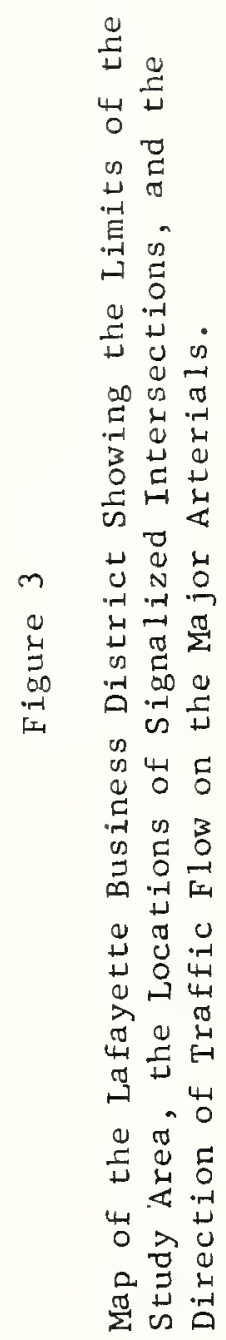




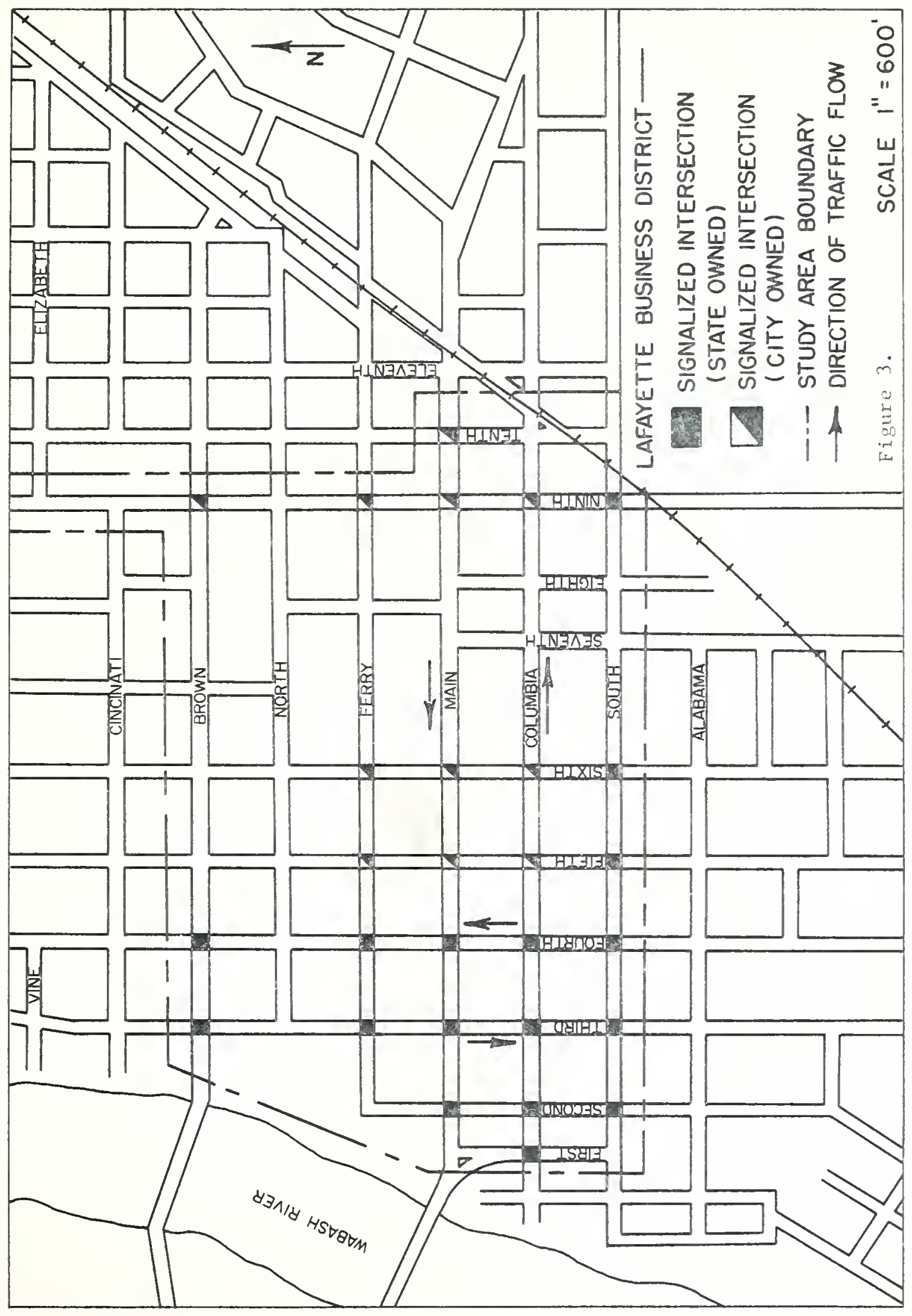




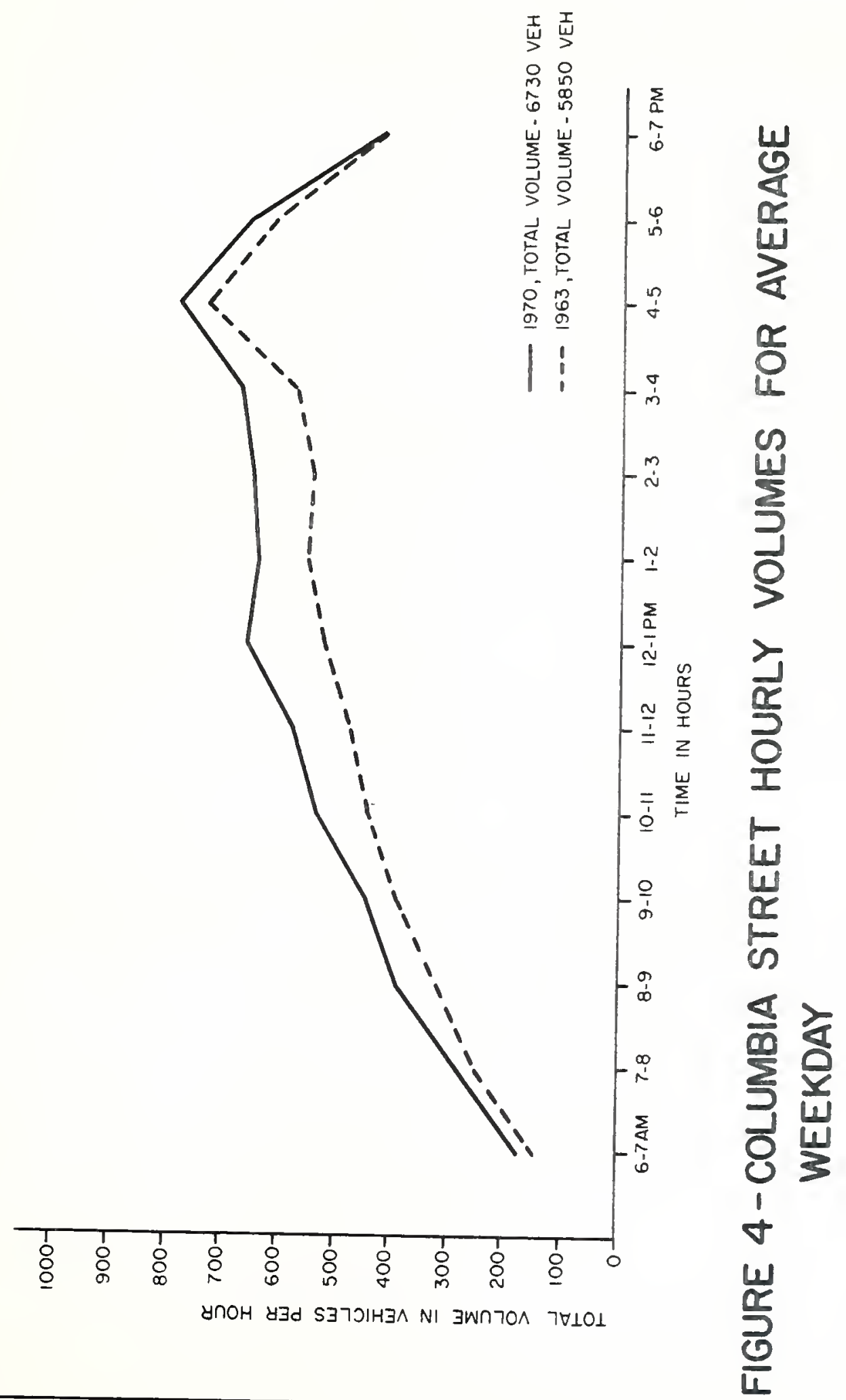


same area at a rate of 7,850 vehicles per 12 hour day for the same time period (Figure 5). Both streets are two lanes with parking permitted on both sides。

The north-south arterials are the one-way couplet of Third and Fourth Streets running through the heart of the CBD, and Ninth Street, a two-way street on the fringe. Third and Fourth Streets were chosen to make runs, in order to check the effect of the systems on cross traffic. Runs were not made in this direction for modes 1, 2, and 3 at the time this project was started in 1963. The before conditions could not be reproduced in 1970; therefore, there is no check on cross traffic for these modes. However, runs were made in the north-south direction for the flexible coordinated mode. This information can be used as the before data at a later time if improvements are made to the system.

Third street is southbound. It is two lanes wide with parking on both sides, and serves 7,790 vehicles per 12 hour day (Figure 6). Fourth Street is northbound. It is also two lanes wide with parking on both sides, and carries 7,860 vehicles per 12 hour day (Figure 7)。

\section{Traffic Signa1 Systems}

Three modes of operation were chosen for comparison with the flexible coordinated system. All are less costly alternatives, the first being uncoordinated and the other two being coordinated.

The signal system being utilized prior to the installation of the new system employed a random mode of operation, wherein each individual intersection was controlled independently by its own local controller with no attempt being made to coordinate operations. With this type of operation, signal timing is tailored to the conditions at the individual 


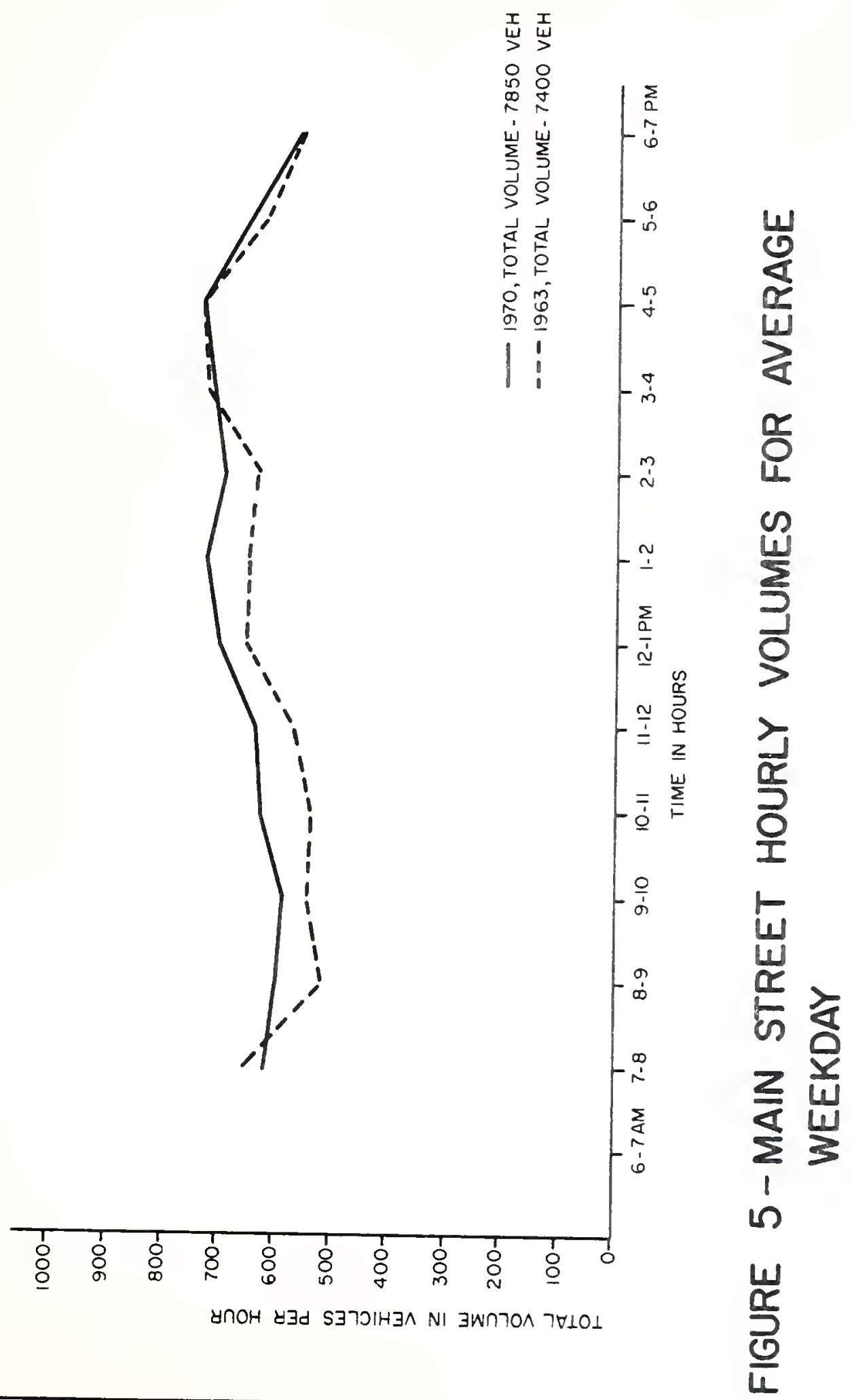




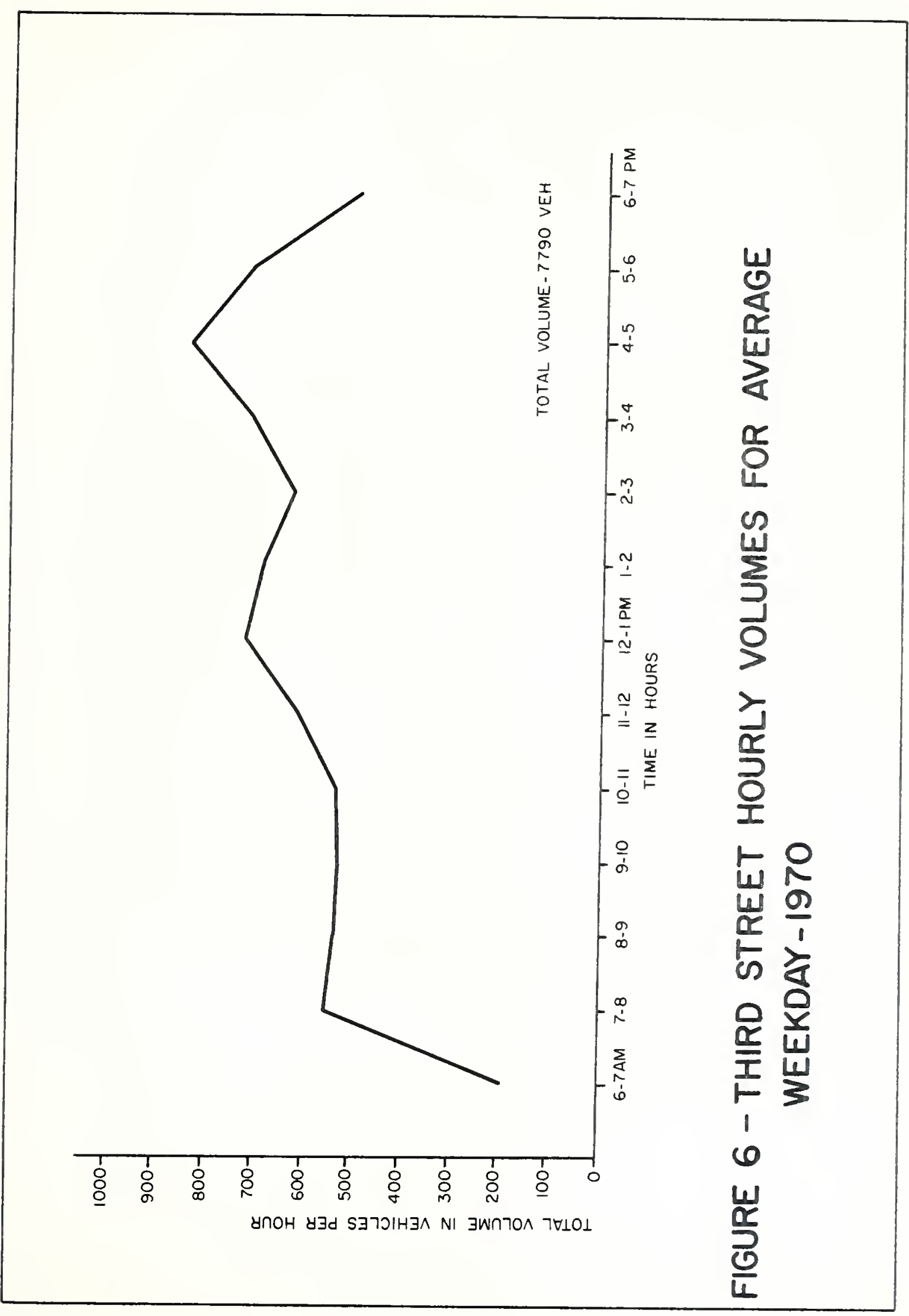




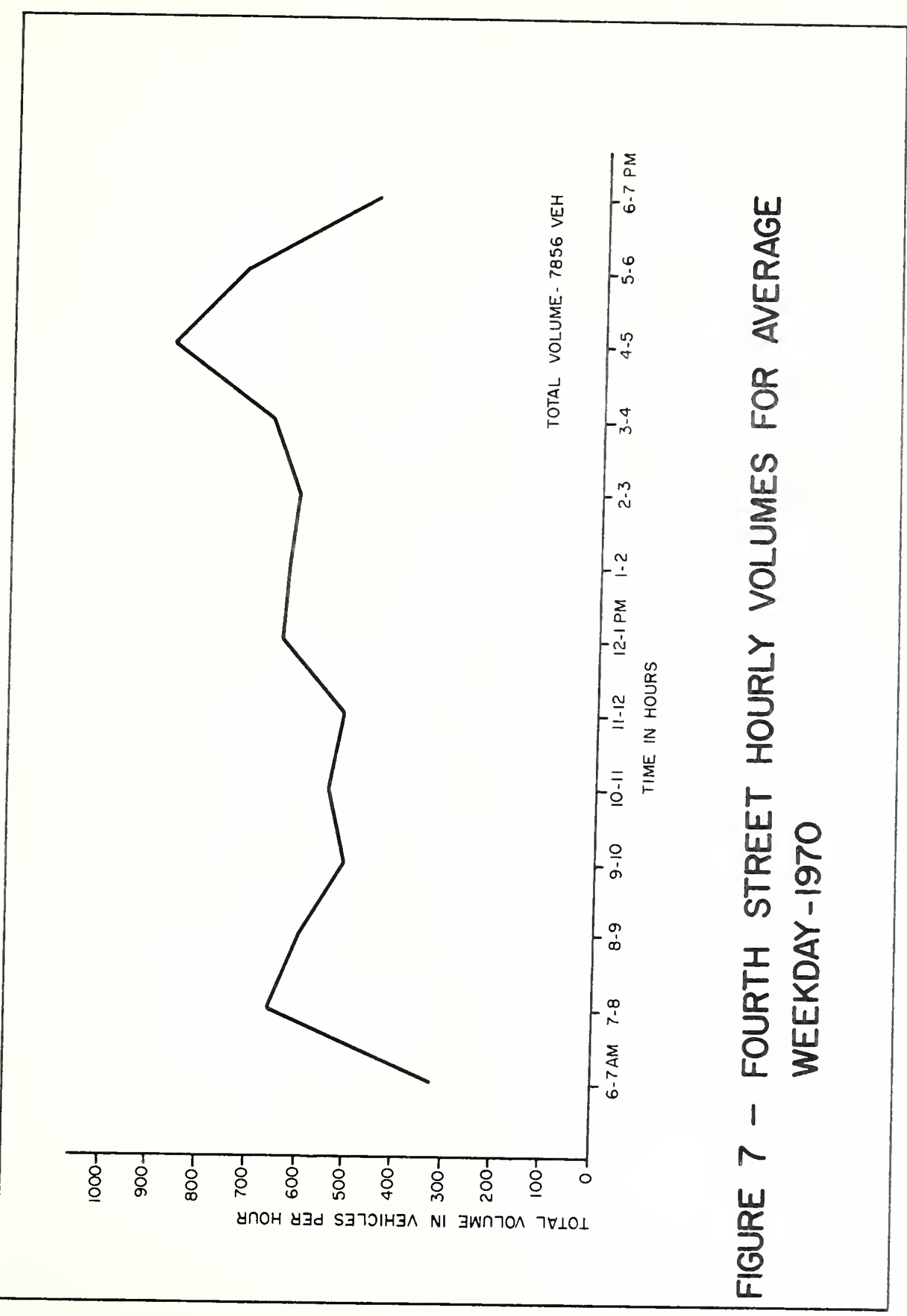


intersections. This allows for many different cycle lengths and splits to be used throughout the system, conceivably as many as there are intersections. Independent operation is desirable for isolated locations where the timing of the signal does not effect adjacent signals, but in general, it is undesirable in highly signalized areas such as the CBD. The uncoordinated system does not establish an orderly pattern of traffic flow since each signal operates as an individual and not as part of a group. Random signal timing is characterized by numerous stops and delays, and low overall travel speeds. This is the basic condition and is referred to as mode 1 throughout the study。

Systems 2 and 3 were fully coordinated operations, but were pretimed. These systems are not capable of responding to actual traffic demands, but are set for a predetermined set of cycle lengths and splits。 This timing is based upon average volume conditions within the system. These systems were simulated with the new equipment prior to its being put into fully automated operation.

System 2 utilized a simultaneous mode of operation. With this method of signal timing, all traffic signals in the system change color indications at the same point in time, with all indications along a given route being the same with the cross streets showing the opposite color. It requires that all signals have the same cycle length and also requires that the same split be used at all locations. This is to say that the minor street is allocated the same percentage of the cycle at all intersections regardless of the traffic distribution. Simultaneous operation is characterized by high speeds between stops, but low over-all speeds. It is also thought to be more efficient at high volumes (near capacity) than other modes. 
A single alternate plan of operation is one in which every other signal indication is the same throughout the system. It also requires a common cycle length and a common split. This scheme of operation is designated as mode 3 .

The fourth system, the object of this study, and the system in operation at the present time in Lafayette, is a flexible coordinated system. It employs a flexible progressive mode of operation, switching to simultaneous operation at high volumes. It was installed in 1963 and utilizes Electromatic PR Coordinated Traffic Control equipment. This equipment is quite flexible in operation, but as all equipment of this type its efficiency is dependent to a great extent upon the skill of the initial programer and the data available to him.

The system consists of four basic components: detection, master control, local control, and interconnection. A schematic diagram of the operation is shown in Figure 8. The obvious advantage that this setup has over the others is the ability to monitor traffic conditions and to adjust to the conditions present on the street system at any given time. Sampling detectors at representative locations in the signal system area continuously provide the master controller with information about traffic performance.

Various combinations of six cycle lengths, five offsets, and three cycle splits can be specified for anticipated conditions of traffic flow. They are put into effect automatically as operating instructions to the local controllers by the master control in accordance with measured changes in traffic demand. 


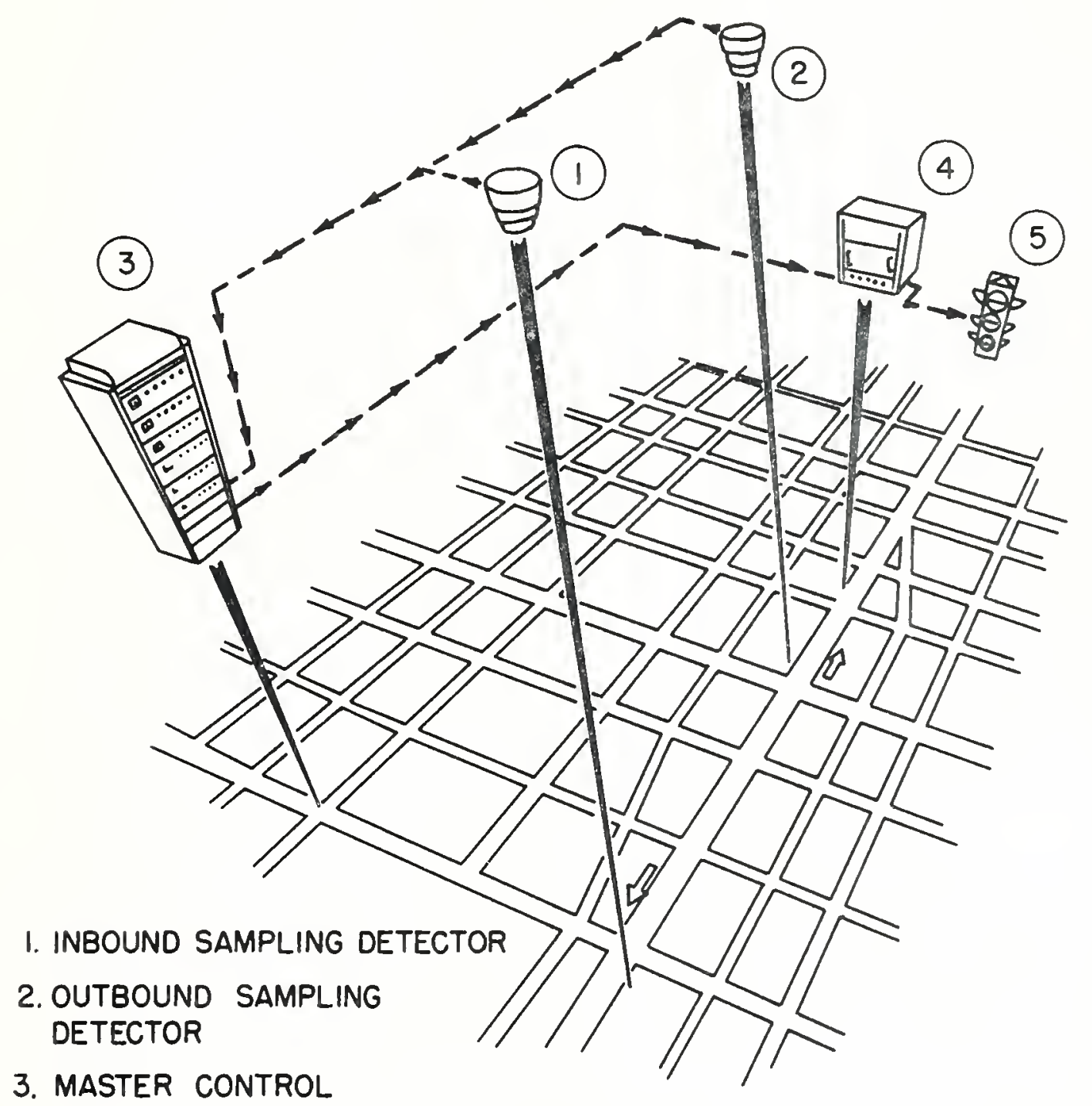

4. LOCAL INTERSECTION CONTROLLER

5. SIGNAL HEAD

FIGURE 8-ELEMENTS OF PR COORDINATED TRAFFIC SIGNAL CONTROL SYSTEM 
Master control and local controller settings are first determined for various probable traffic conditions through the use of time-space diagrams. Cycles, offsets, and splits for inbound, outbound, and average traffic on an arterial street may be provided for by the settings of the master controller and local controllers. In a grid system the settings may provide for favoring either north-south or east-west traffic when required, with compromise settings for periods of equal demand in both directions.

As the total traffic in the system varies during the day between minimum and maximum values, as many as six different cycle lengths can be used in the range of 40 to 120 seconds (16.).

Proper location of sampling detectors is essential for a vehicle responsive system such as this. This is of primary importance since the detection phase of the operation must supply information to the computer that is representative of the actual conditions that exist on the street system at any given time. Detectors should be located with reference to the major traffic flow with which they are associated. A detector for outbound traffic measurement should be located where it will show a definite outbound movement (16). When possible it is desirable to have duplicate sampling points to compensate for the effect of circuit failure, street repairs, accidents, or other interruptions at any one sampling location. Detectors should be located on free flowing streets far enough from the system to give the master control ample time to adjust for varying levels of detection. Free flowing streets are required since a false indication of light traffic could be interpreted on a street that experienced much congestion and slow moving or stopped 
traffic. The Lafayette system employs radar detectors at the locations shown in Figure 9.

Sampling detector information is relayed to the master control unit which is housed in the Traffic Improvement Department headquarters building shown on Figure 9. This unit and its component parts are shown in Figure 10. The installation is made up of two cycle computers, one system selector, one cycle generator, one switching panel, one system supervisor, one amplifier, and a power supply.

While one of the two computers is capable of responding to from one to four inbound detectors, the other can be responsive to from one to four outbound detectors. Each computer selects a cycle length based upon the average detected volume. The system selector then selects the longer of the two cycle lengths and determines the offset based upon the difference in the two computed cycle lengths.

Example 1: Inbound computer selects - Cycle B

The system selector then selects Cycle E Since it is the longer of the two. Cycle lengths are designated by A, B, C, D, E, and $\mathrm{F}$; therefore, there are three steps between $B$ and $E$. This tells the system selector that outbound traffic is much heavier than inbound traffic. The selector then chooses the outbound offset which favors outbound traffic。

Example 2: Inbound computer selects - Cycle C Outbound computer selects - Cycle C

System selector selects - Cycle C and average offset.

This information is then sent out as operating instructions to the local intersection controllers. 


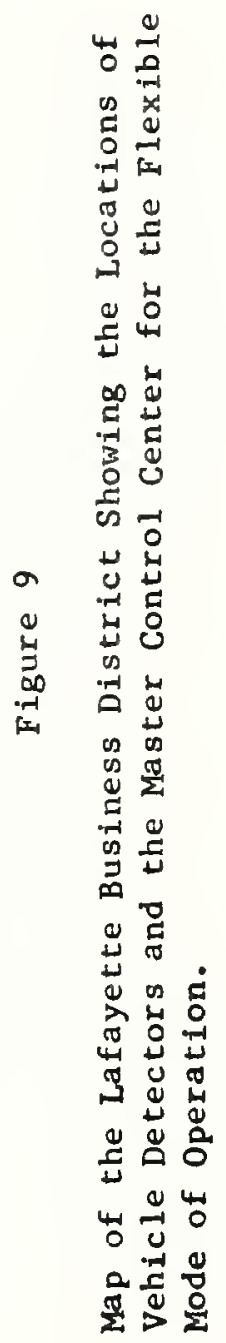




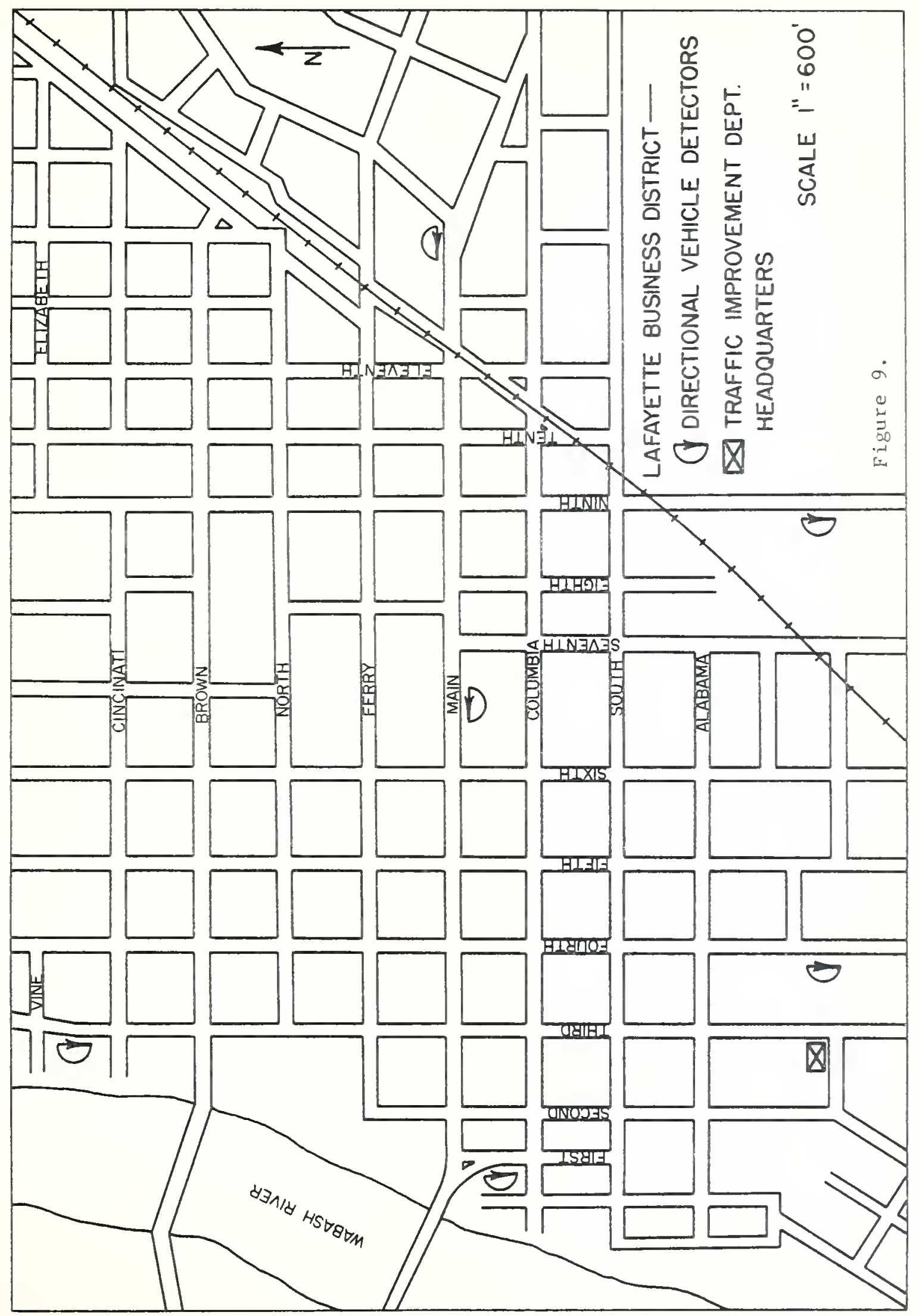


MC-11 Cycle Computers (shown) or MC-4l Vehicle Density Cycle Selector and

M-107 Radar Speed and Impulse Translators

MC-15B System Selector

MC-12C Cycle Generator

Switching Panel

MC-31 System Supervisor

MC-23A Dual Amplifler

MC-22 Generator-Translator

MC-24A Power Supply and Converter
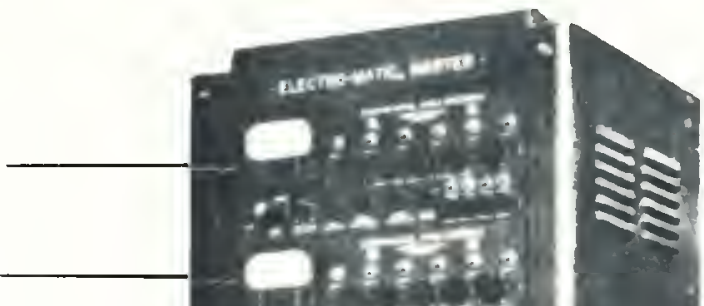

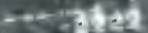

?

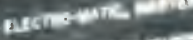

, $3,30,9$

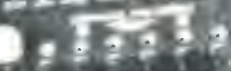

1. prover

is $=$

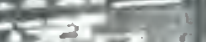

$+$

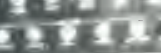
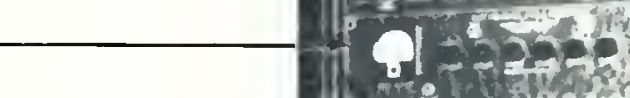

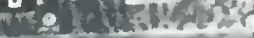

3.
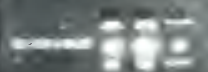

ches:
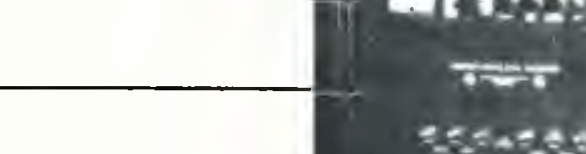

क्षात

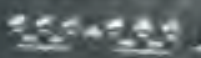

$\rightarrow \frac{1}{2}$

axt:- +ote

mores-
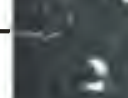

Flltered Cablnet Cooling Fan

\section{FIGURE IO-MASTER CONTROLLER}


The local controller receives the master control command and responds to it at the individual intersection. Additional flexibility is provided through use of dial settings at the local controller. Each local controller has provisions for setting three different cycle splits. These split settings are associated with offsets by means of switches on the controller. A single split can be used for all offsets, or any one of the three available splits can be associated with any desired offset. Pedestrian clearance intervals and special intervals such as advance green or al1 red clearance periods can also be provided by dial settings. Interconnection of circuits was accomplished through the use of telephone lines. For a detailed explanation of this system's operation see reference 16 . 
DATA COLLECTION

The data consists of travel time runs over the range of volumes within the system for each of the four modes of signal operation, and volumes collected simultaneous to the travel times. Spot speeds were also taken at various points within the system.

The east-west route chosen for the runs is shown in Figure 11. The route consists of Main Street (westbound) and Columbia Street (eastbound). These streets were used because they pass through the study area and they are the most heavily traveled arterials of the area.

As the test vehicle passed the point designated as A (Figure 11) timing for the Columbia street run was started. This run is a total of 4,695 feet in length and passes through seven signalized intersections. Point B marks the end of timing for the Columbia Street run. The Main Street run starts at this point (point B) and is terminated at point A, where the next Columbia Street run is initialized. The Main Street run is 4,465 feet in length and also passes through seven signalized intersections.

Third (southbound) and Fourth (northbound) Streets were used to make the north-south travel time runs for the same reasons Main and Columbia Streets were chosen. The Third Street times were begun at point $C$ and ended at point $D$. This 1 eg of the route passes through 


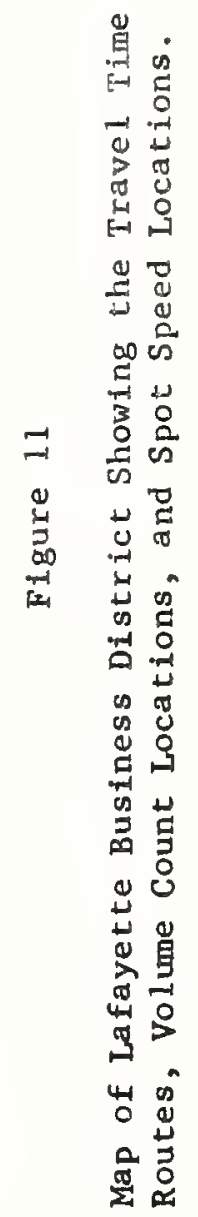




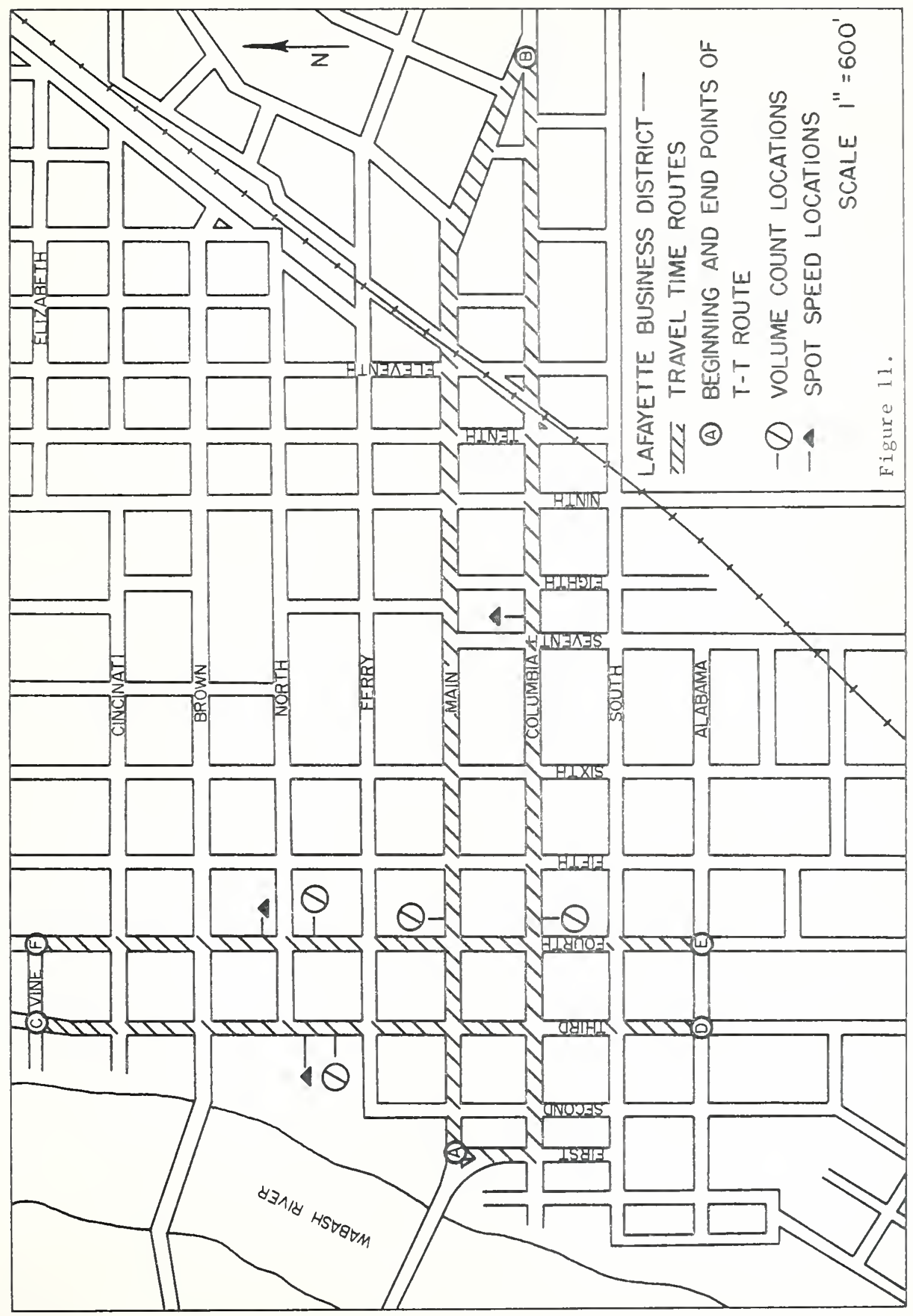


five signalized intersections and is 2,360 feet in length. The Fourth Street run began at point $\mathrm{E}$ and ended at point $\mathrm{F}$, also passing through five signalized intersections and being 2,345 feet in length.

The "average car" method was used in the collection of travel time data since for a given sample size this method was found to produce better statistical results than other methods when used on heavily traveled multi-lane streets (5). At least 50 runs were made on each segment of the route, as this was found to be the sample size required to achieve five percent accuracy in determining tavel times for multilane congested streets (Table 1). Times at which runs were to be made were determined in such a way that all classes over the entire range of volumes would be represented in the final sample. This included peak times, off peak times, and times on weekdays and weekends. The runs were also conducted at approximately the same times for each mode so that travel conditions would be made as nearly the same for all modes as possible, so as not to bias the results with runs made under different conditions for different modes.

A Streeter-Amet travel time-distance recorder (Figure 12) was used to record the times. This device consists of a timing mechanism and printing device that marks a paper tape when activated. Up to 12 events can also be recorded through the use of the keyboard shown in Figure 12. The following is an explanation of the use of the machine. The timing device is set to zero and started. The machine counts continuously but prints only when activated through a switch on the keyboard. When an event is to be recorded the number of the event is depressed and the printer is activated. A record of the event and the time (in hundreths 
Table 1. Samples Needed for Determining Mean Over-All Speeds on Selected Test Sections within Different Limits for 95 Percent Degree of Confidence

\begin{tabular}{|c|c|c|c|}
\hline \multirow{3}{*}{ Test Section } & \multirow{3}{*}{$\begin{array}{c}\text { License-Check Studies } \\
\text { Sample Size } \\
\text { for } 5 \% \\
\text { Accuracy }\end{array}$} & \multicolumn{2}{|c|}{ Test-Car Runs } \\
\hline & & \multicolumn{2}{|c|}{$\begin{array}{c}\text { Number Needed for } \\
\text { Accuracy of }\end{array}$} \\
\hline & & $5 \%$ & $10 \%$ \\
\hline \multicolumn{4}{|l|}{ Signalized Urban Streets } \\
\hline 1. Two-lane, uncongested & 32 & 30 & 8 \\
\hline 2. Two-lane, congested & 36 & 40 & 10 \\
\hline 3. Multi-lane, uncongested & 80 & 18 & 5 \\
\hline 4. Multi-lane, congested & 102 & 50 & 13 \\
\hline \multicolumn{4}{|l|}{ Rural Sections } \\
\hline 5. Two-lane, $1130 \mathrm{VPH}$ & 25 & 25 & 6 \\
\hline 6. Two-lane, $1440 \mathrm{VPH}$ & 41 & 42 & 11 \\
\hline 7. Four-lane, uncongested & 30 & - & - \\
\hline
\end{tabular}

Source: Reference No. 5

Note: Five percent accuracy refers to values being within five percent of the true mean speed. 


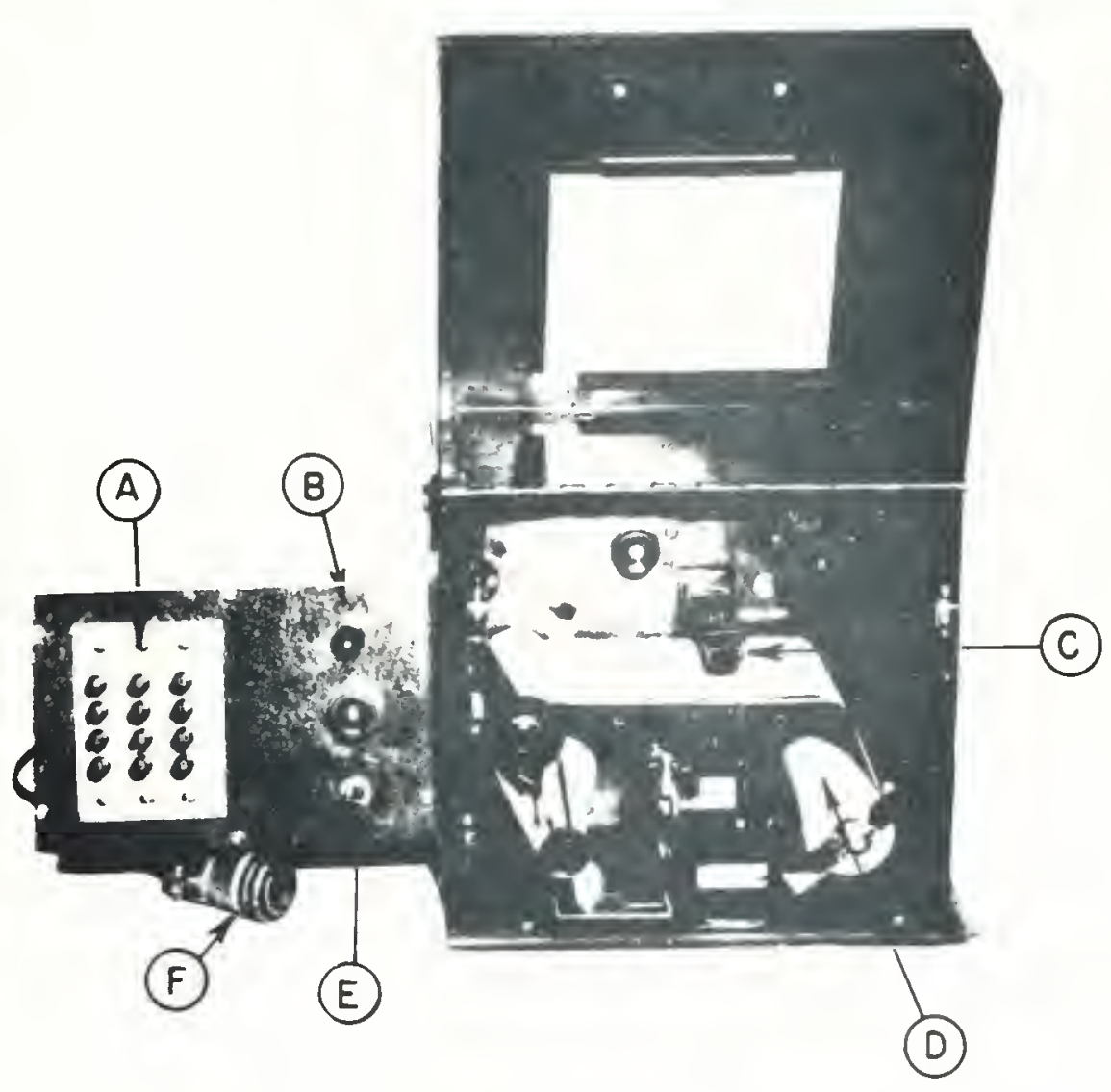

A. EVENT CODE KEYBOARD

B. ACTIVATES COUNTING MECHANISM

C. PRINTING ARM

D. PAPER TAPE

E. ACTIVATES PRINTING MECHANISM

F. INTERCONNECTING CABLE

FIGURE 12 - TRAVEL - TIME AND DISTANCE RECORDER 
of minutes) at which it occurred are recorded on the paper tape (Eigure 13). The device also has facilities for recording distances through a fifth wheel, but it was not used since all the runs were made on the same routes and all pertinent distances were known. The event code is shown in Figure 14. The events recorded are as follows:

$$
\begin{aligned}
& \text { 1. Start of run } \\
& \text { 2. End of run } \\
& \text { 3. Centerline of signalized intersection } \\
& \text { 4. Signal delay } \\
& \text { 5. Pedestrian delay } \\
& \text { 6. Turning car delay } \\
& \text { 7. Parking car delay } \\
& \text { 8. Train delay }
\end{aligned}
$$

All delays are stopped time delays, with no attempt being made to determine acceleration and deceleration delays.

Continuous manual volume counts for one minute intervals were recorded simultaneous to travel time runs on each route so that volumes and travel times for the individual segments of the routes could be correlated. Also pneumatic tube vehicle counters were employed at the same location (Figure 11) so that a check on volumes could be obtained. Synchronized watches were used at all times by all members of the data collection team。

Spot speeds were also checked at various locations throughout the system for the flexible mode (Figure 11). These checks were made along lengthy unsignalized sections of the system to determine the average running speed of the traffic. A radar meter was employed to lake a sample of at least 100 speeds during off peak conditions. 


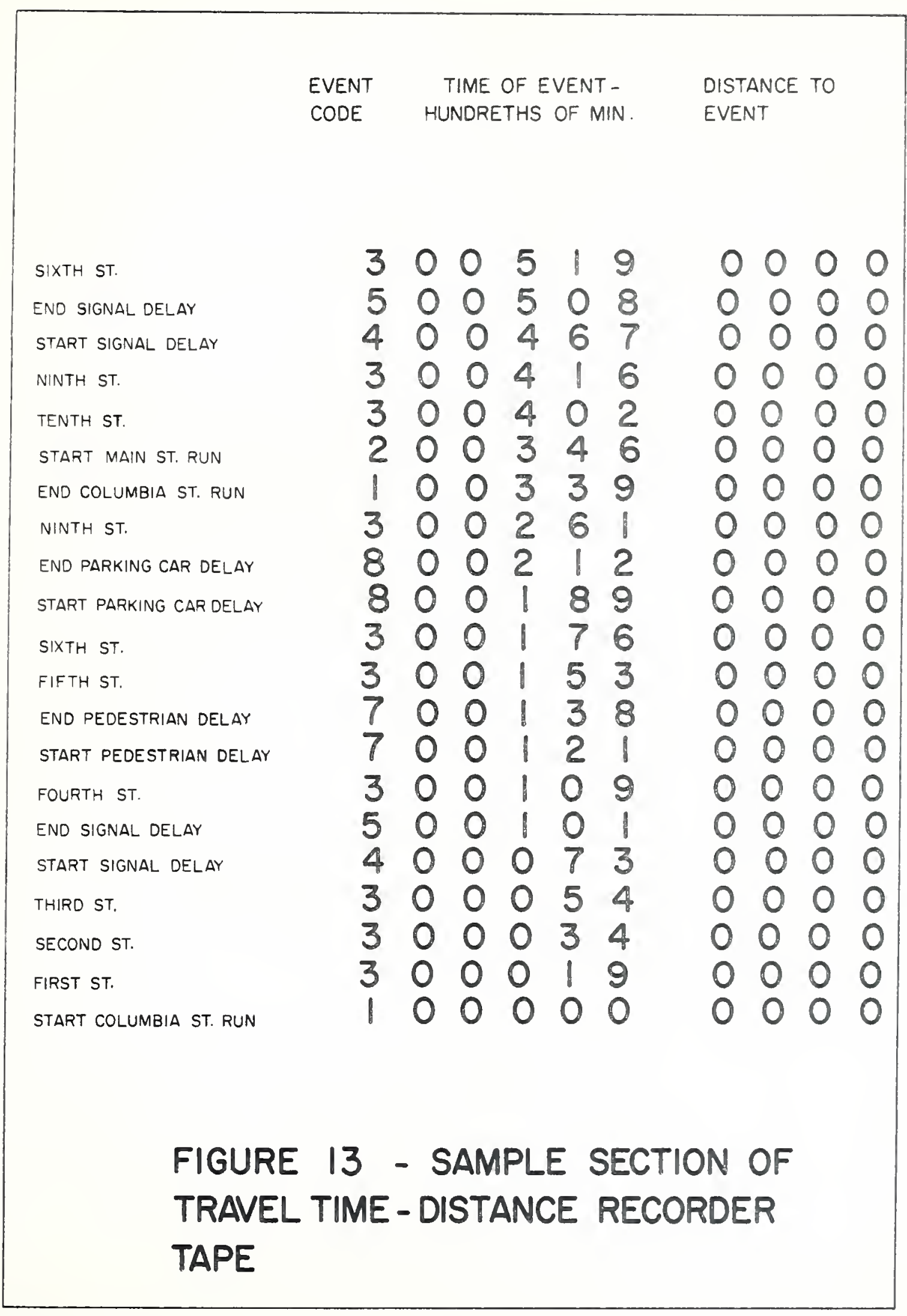




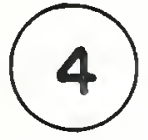

BEGINNING OF SIGNAL DELAY

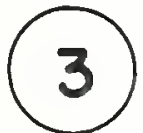

CENTERLINE OF SIGNALIZED INTERSECTION

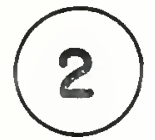

BEGIN AND END MAIN ST. RUN

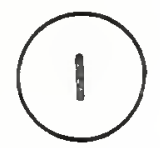

BEGIN AND END COLUMBIA STT. RUN

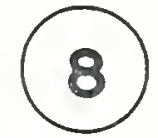

BEGIN AND END PARKING CAR DELAY

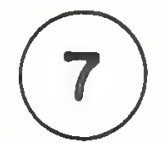

BEGIN AND END

PEDESTRIAN DELAY

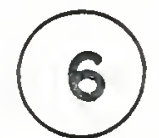

BEGIN AND END

TURNING CAR DELAY
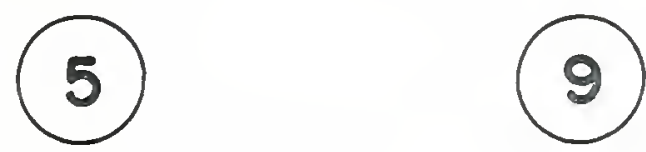

END OF

SIGNAL DELAY

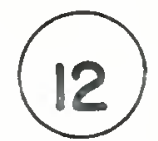

CANCEL RUN

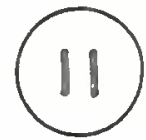

10

BEGIN AND END TRAIN DELAY

\section{9}

FIGURE 14-EVENT CODE 
DATA REDUCTION

\section{Volume Data}

Through the use of synchronized watches it was possible to determine the volumes that were recorded coincident to each run. The volumes recorded for a given run were then averaged, and an expansion factor was applied to obtain an hourly volume. In this manner an effective hourly total volume was associated with each travel run. These volumes were generally more variable than actual volumes recorded by the traffic counters at the same location. This is due to the fact that this method of volume determination reflects the effects of minute to minute fluctuations more readily than hourly counts. This was desirable since concern was with the effective hourly volumes that prevailed during each run, and not actual hourly volumes.

Even though this method is helpful in detecting momentary fluctuations it still does not reflect the true nature of actual test vehicle conditions in all cases. In some instances a low volume calculated according to this procedure will actually seem to be much higher to the test vehicle because of conditions of congestion in the immediate vicinity of the vehicle. The method of volume determination needs to be refined to give volumes that are a truer reflection of what the test car actually experiences for each run. A congestion index could be developed to supplement the volume data. This factor was not recognized until the 
analysis was under way. The extent of its effect was not determined, since it was not included within the scope of the project.

The following equation was used for computing volumes:

$$
(\mathrm{EHV})_{i}=(\mathrm{AVM})_{i} \times(\mathrm{EF})
$$

where $(E V H)_{i}$ is the effective hourly volume for run $i,(A V M)_{i}$ is the average volume per minute for the time the run was being made, and (EF) is an hourly expansion factor. An example follows:

$\begin{array}{cc}\text { Data from Volume Recording Sheet } \\ \text { Time } & \text { Volume } \\ 3: 36 & 11 \\ 3: 37 & 9 \\ 3: 38 & 12 \\ 3: 39 & 13 \\ 3: 40 & 15 \\ 3: 41 & 12 \\ 3: 42 & 10 \\ 3: 43 & 11\end{array}$

From the trave 1 time recorder it is determined that a run was made from 3:36 to 3:40; using the volumes recorded for these times the following is obtained.

$$
(\mathrm{EHV})_{i}=\left(\frac{9+12+13+15}{4}\right) \times \quad \text { X } 60=735 \mathrm{VPH}
$$

The result is the effective hourly volume to be associated with this run in the analysis.

\section{Travel Time Data}

Data for travel time for each segment between signals and the delays experienced were recorded individually then punched in the same format on computer cards. A program called AVGVAR was developed that accepted data in the previously mentioned format, summarized the data for each 
run, and punched out cards in a six variable format for each run. The variables were as follows:

1. Volume, V

2. Total travel time, TT

3. Delay time, DT

4. Running time, RT

5. Stops per run, S

6. Average time per stop, TS

As a result of this procedure, each run was completely described by a single punched card so that the analysis might be facilitated. Also included on the card was a two digit identification number. The Eirst digit was coded to represent the street upon which the run was made, and the second digit, the signal mode which was in effect during the run. The following code was used:

\section{$\underline{\text { Streets }}$}

Columbia 1

Main

Third

Fourth

\section{Signa 1 Modes}

Random 1

Simultaneous 2 Alternate $\quad 3$

Flexible
4

A card displaying 23 in the identification field would indicate a run made on Main Street while the alternate mode of operation was in effect.

Eventually a decision was made to reduce the length of the travel time routes. In most cases the run was initialized or terminated by a long section of unsignalized roadway. Since travel times for these 
sections are not influenced by signal modes the routes were shortened to begin at the centerline of the first signalized intersection and end at the centerline of the last signalized intersection of each route (Figure 15). This procedure produced the desirable result of eliminating the stops made at the first signal on each route. Arrivals at the first signal are dependent upon chance and not signal timing, since vehicles outside the bounds of the coordinated system are beyond the realm of its control. Contributing to randomness of arrivals are long unsignalized approaches to the system. 


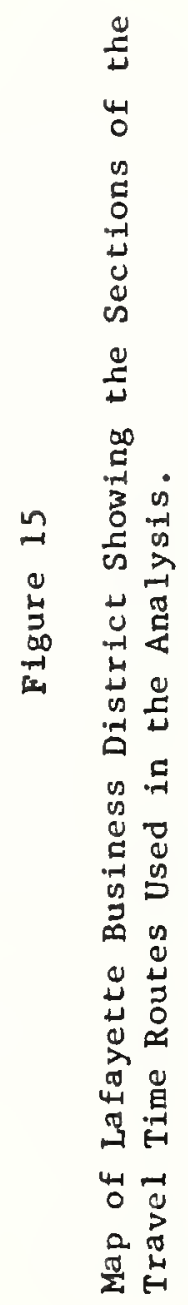




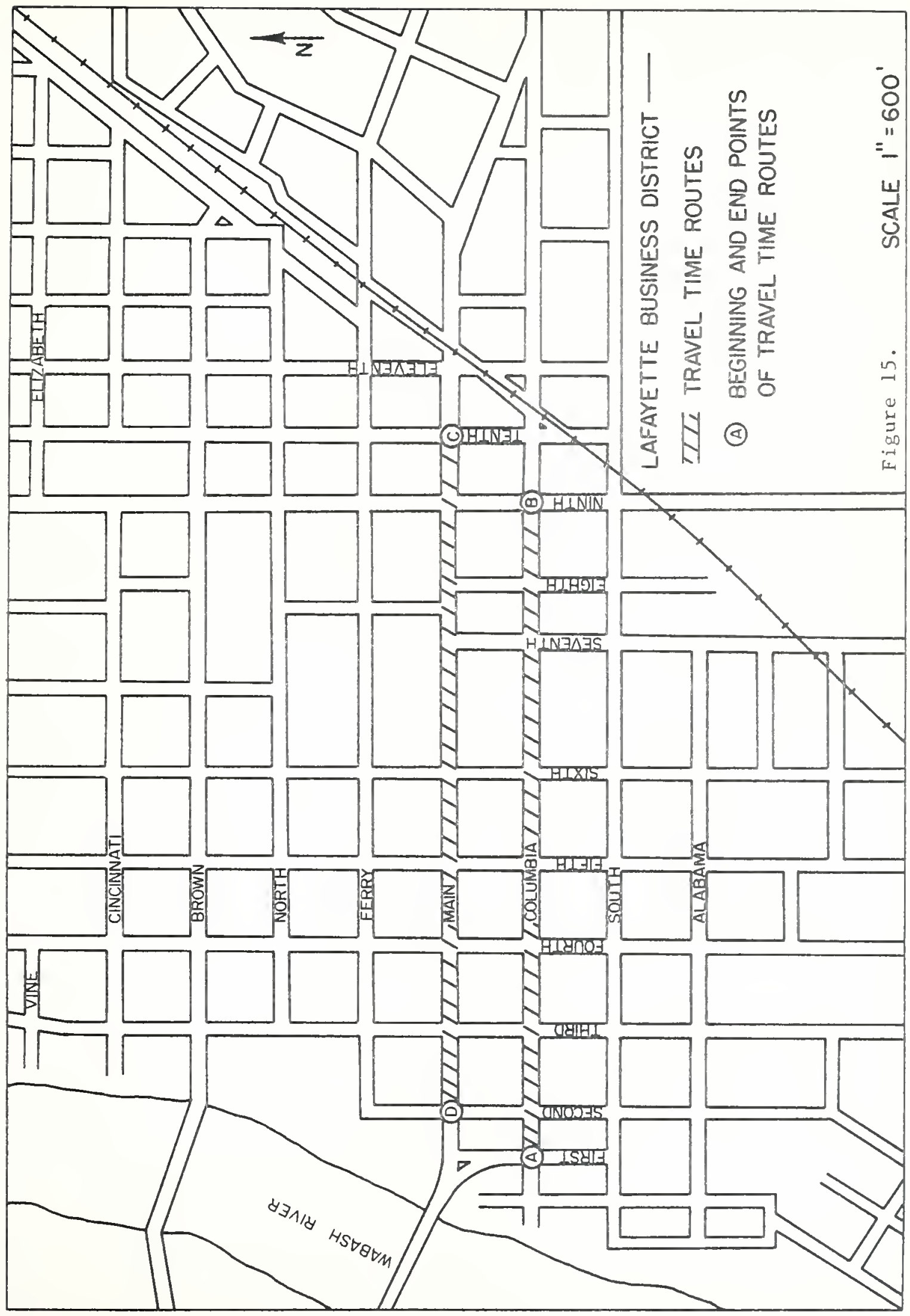


ANALYSIS OF DATA

\section{Analysis of Variance}

An analysis of variance (ANOVA) is based upon a separation of the variation of all the observations into parts, each of which measures variability attributable to some specific source (17). The purpose of this sample variance breakdown is a comparison of the means of each population of the analysis.

In order that a true comparison of the signal modes could be obtained, and as a first step in the analysis, runs that involved all other types of delays were discarded. This enabled the delays and stops attributable only to signal timing to be determined, giving a more realistic comparison of modes than if delays caused by pedestrians, parking cars, etc. were included in the analysis. These delays, which are common to al1 modes, would generally occur randomly and independent of signal timing.

The data were then classified according to volume levels in order to perform a two-way ANOVA. The two-way analysis is designed to study populations classified by two characteristics. In this research the variables were grouped according to volumes and signal modes. A volume class interval of 100 was found to give a workable cell size distribution, since a larger class size gave too few volume classes and a smaller class size allowed too many empty cells. However, some cells were rearranged 
and combined in order to avoid empty cells and cells with no replication. For the results obtained from the ANOVA to be meaningful certain basic assumptions should be met. The F-test (the test performed to determine significance of main effects and interactions) performed in the ANOVA assumes homogeneous variances among the several populations; therefore, variances of the variables listed in DATA REDUCTION were tested for homogeneity. This check was done on a CDC 6500 computer utilizing the Datasum program (18). Datasum is a library program that summarizes data and computes various statistics from the data. Two homogeneity of variance tests (Bartlett's test and the Foster-Burr test) are also performed. Using the chi-square values resulting from Bartlett's test three of the six variables were shown to have heterogeneous variances. Several data transformations were used with no significant improvement in the test result shown.

Inspection of the individual cell variances showed the variances of cells within the random mode to be much more variable than the remaining data. This combined with the presence of empty cells at the higher volume levels, and undesirable effects upon the initial ANOVA, resulted in the decision to exclude the random mode from further consideration in the analysis. This will not adversely affect the final outcome since a random mode of operation utilized in the $C B D$ would undoubtedly yield the highest motorist costs. The two lowest volume classes for Columbia street were also deleted because of heterogeneous variances due to small numbers of observations in these cells. The final sample classified according to signal modes and volumes is shown in Table 2. Using this arrangement the homogeneity test was performed again yielding the result shown in 

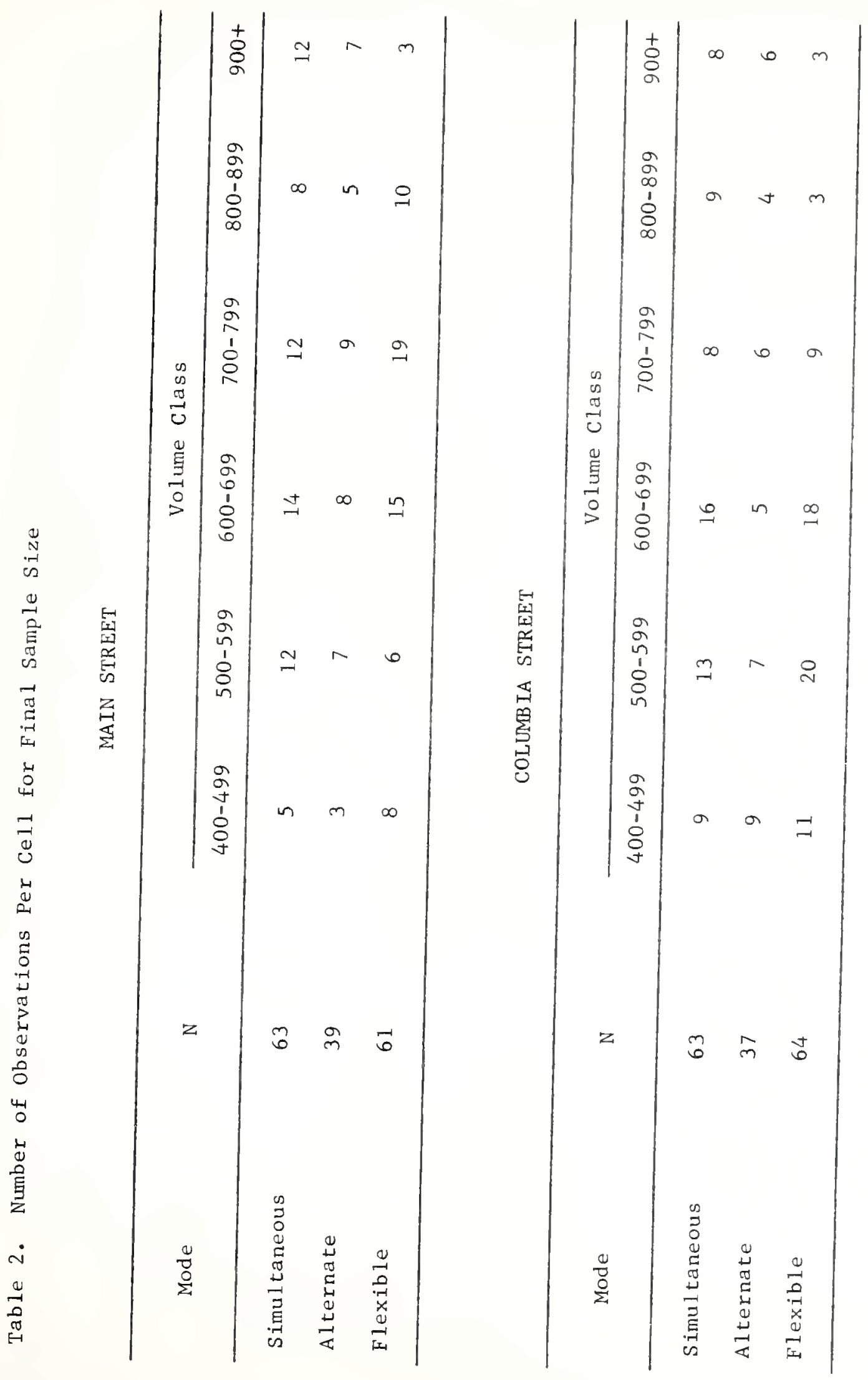
Table 3. All the variables displayed homogeneous variances at the level $\alpha=0.001$ except DT and TS; however, of these two variables only DT is used in the economic analysis. In spite of this lack of variance homogeneity for the variable DT the result of its ANOVA is considered to be reliable. Due to the robust nature of the ANOVA it is capable of withstanding quite a degree of heteroscedasticity (19).

The ANOVA was performed using the Purdue University library program Unequal (20). This program is designed for a two-way ANOVA problem with unequal numbers of observations in the cells. The analys is is based upon section 4.4 of Henry Scheffé: The Analysis of Variance.

The final classification yielded a three by six analysis for both Main and Columbia Streets. The three modes of operation were simultaneous, alternate, and flexible, and the volumes covered six classes with a range from 400 to 1,100 vehicles per hour. The data resulting from the individual travel time routes were analysed independently.

The ANOVA models took the form:

$$
\mathrm{Y}_{i j k}=\mu+\mathrm{M}_{i}+\mathrm{V}_{j}+(M V)_{i j}+\mathrm{e}_{(i j) k}
$$

where:

$$
\begin{aligned}
& Y_{i j k} \text { is the variable under consideration for the } i \text {-th } \\
& \text { mode, the } j \text {-th volume level, and the } k \text {-th obser- } \\
& \text { vation in the }(i, j) \text {-th cell. } \\
& \mu \quad \text { is the variable mean effect. } \\
& M_{i} \text { is the effect of the } i \text {-th mode. } i=1 \text { to } 3 \text {. } \\
& V_{j} \text { is the effect of the } j \text {-th volume level. } j=1 \text { to } 6 \text {. } \\
& (M V)_{i j} \text { is the effect of interactions between the } i-t h
\end{aligned}
$$



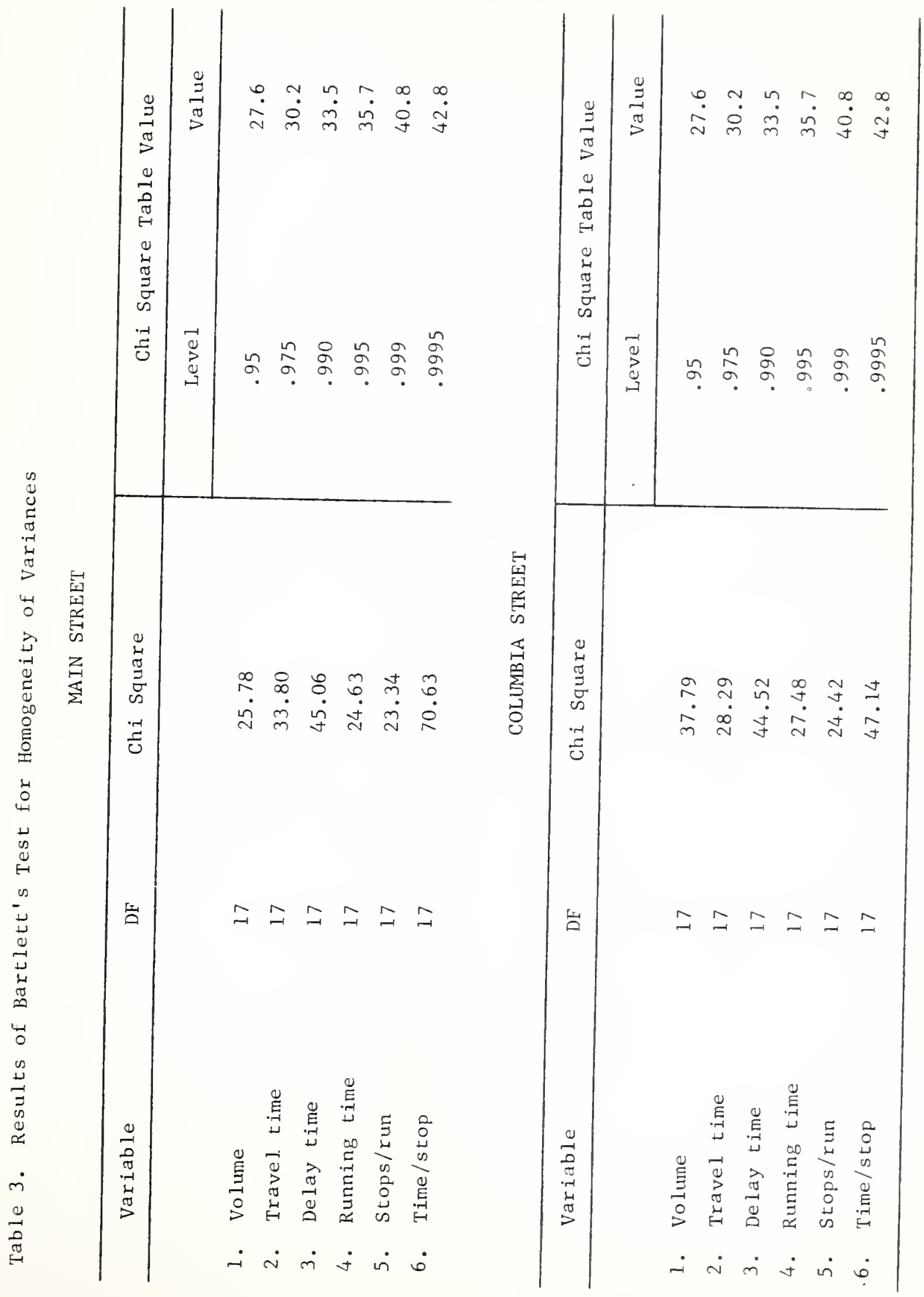


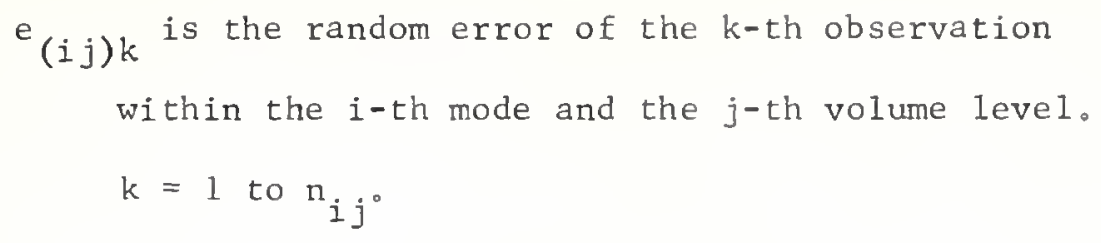

The numerical results of the ANOVA are expressed in Tables 4 through 8. The effects of modes and of volumes are shown to be significant at the level $\alpha=0.10$ in al1 cases except one. Modes were found to have a insignificant effect upon the variable TS (Table 8). This departure from the results of the ANOVA on the other variables (significant modes effect) does not produce an undesirable effect, since the variable TS is not independent and was not used in the economic analysis. An insignificant interaction term is exhibited in all cases. This shows that modes retain their relative rank across the full range of volumes. At no point within the range of volumes does either the simultaneous or the alternate mode give better results than the flexible mode. A graphical representation of insignificant interaction is shown in Figures 16 and 17. These graphs were obtained by plotting the results of a simple linear regression on the cell means for the variables TT and V. The same result could have been obtained using any one of the five variables in the analysis. Interaction in the ANOVA would be depicted as intersection points on the lines of the graphs. The intersection near the upper Iimit on the Main Street graph is not strong enough to produce a significant effect.

The fact that no significant interaction exists makes it possible that the tests for differences in means be made using grand means for each mode and not individual cell means. Since there is an unequal number of observations in each cell, a method that compensates for 


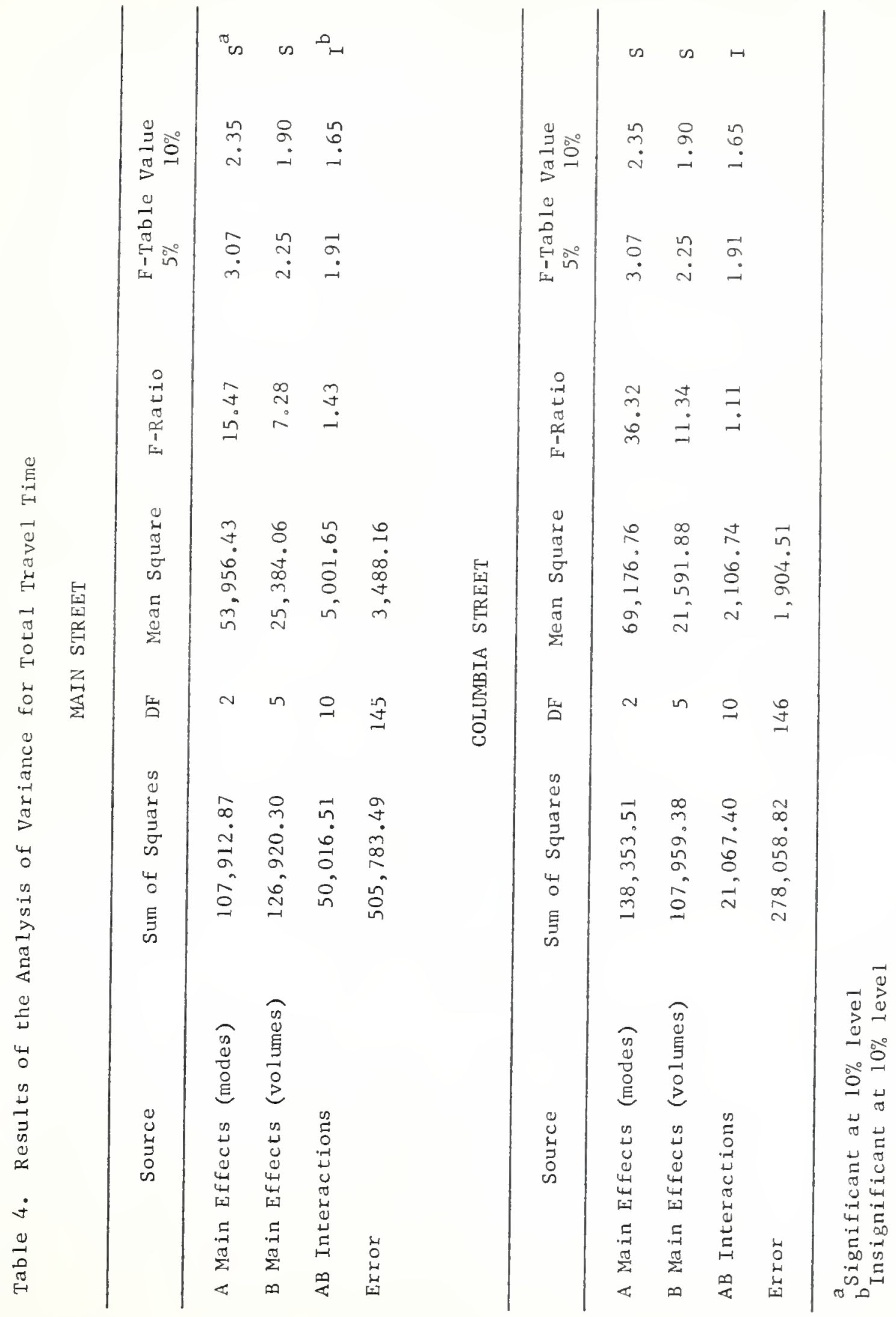




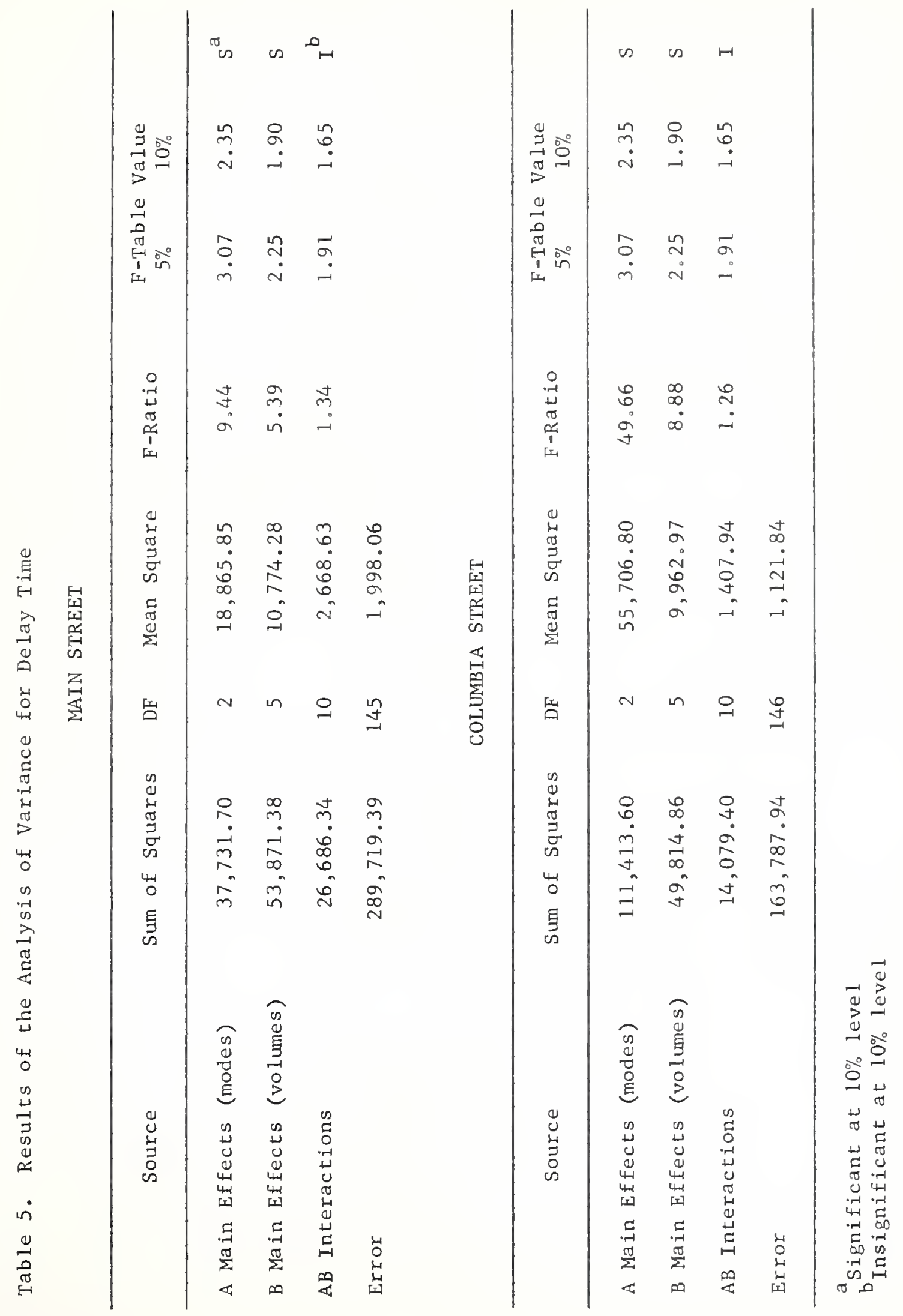




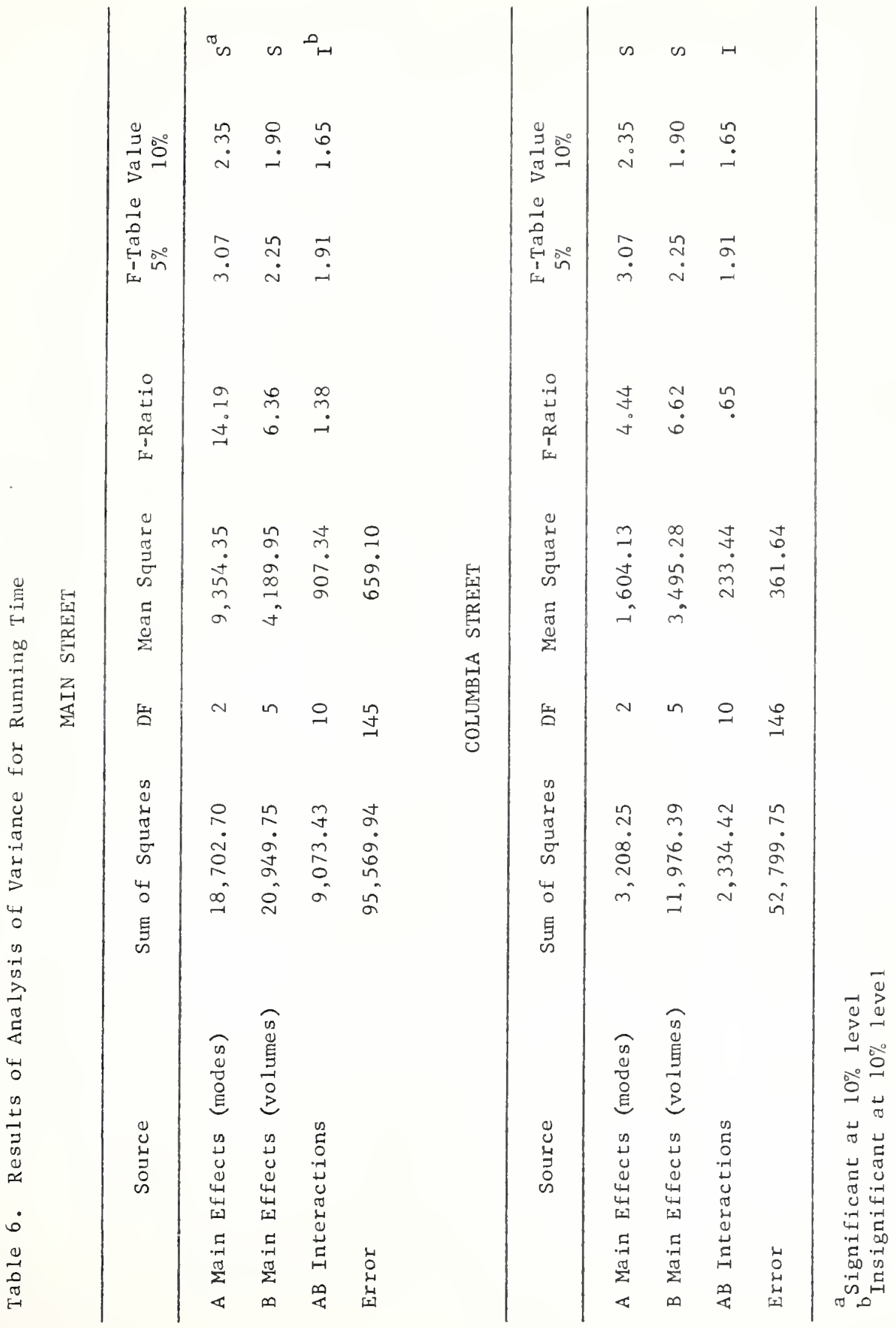



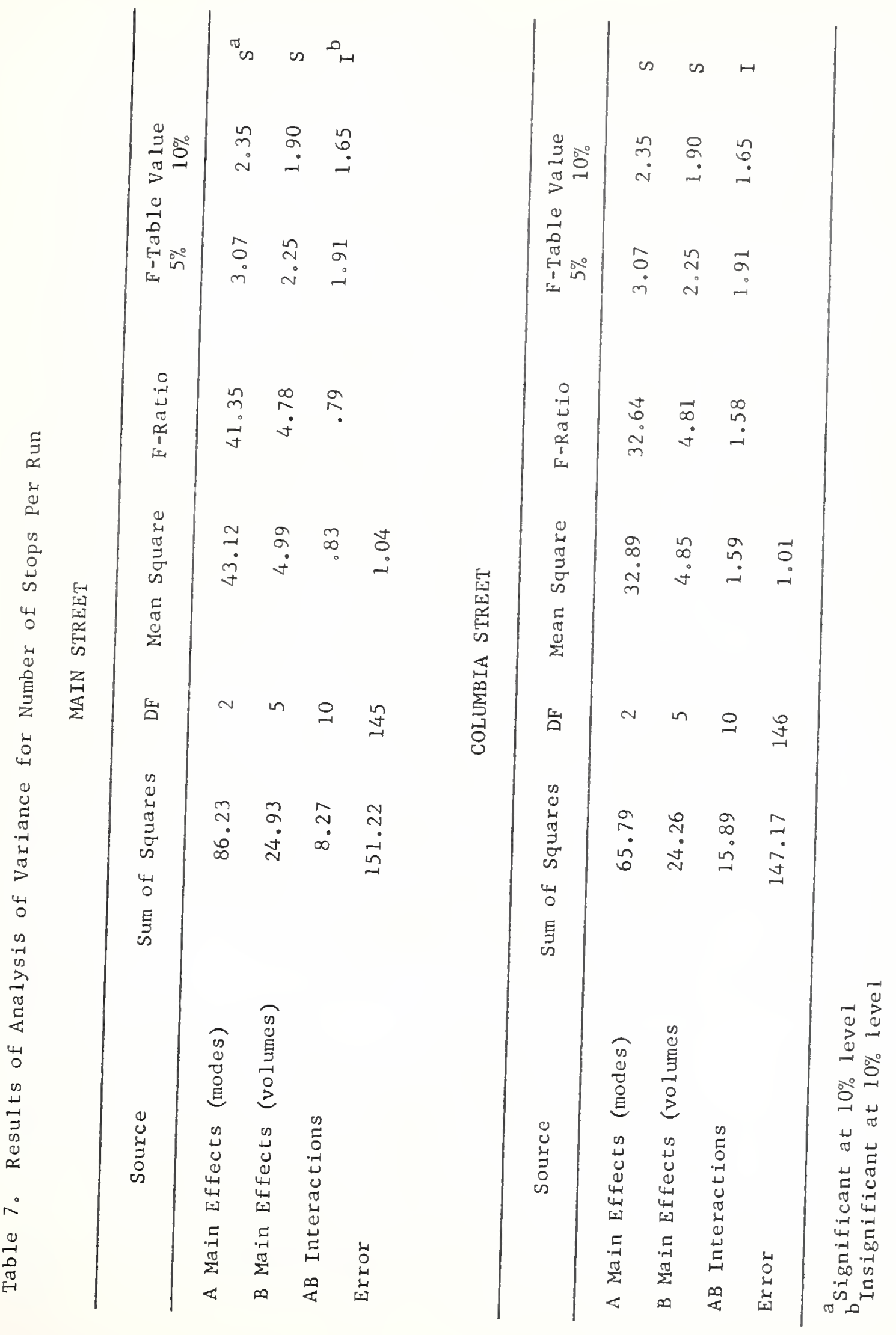

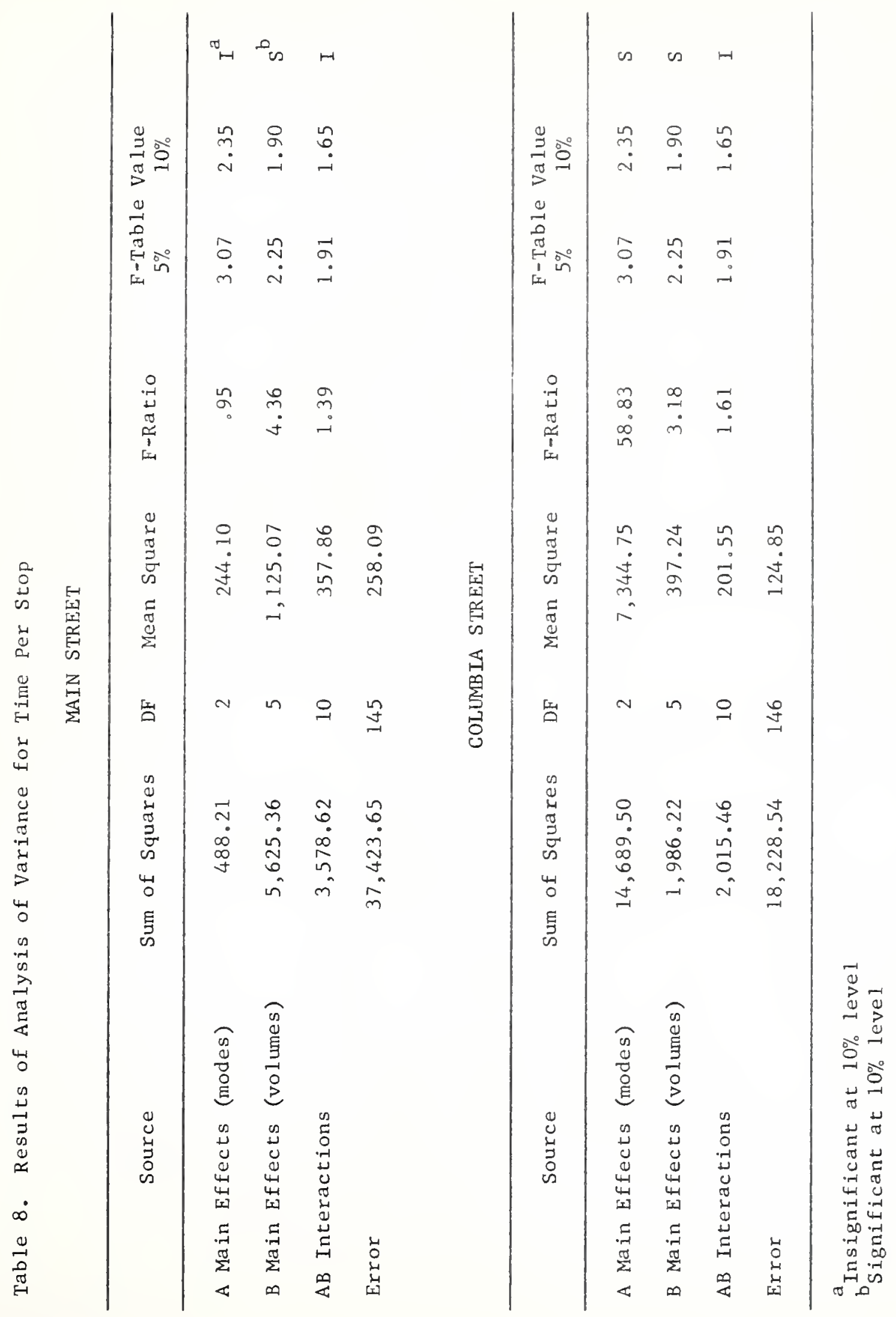


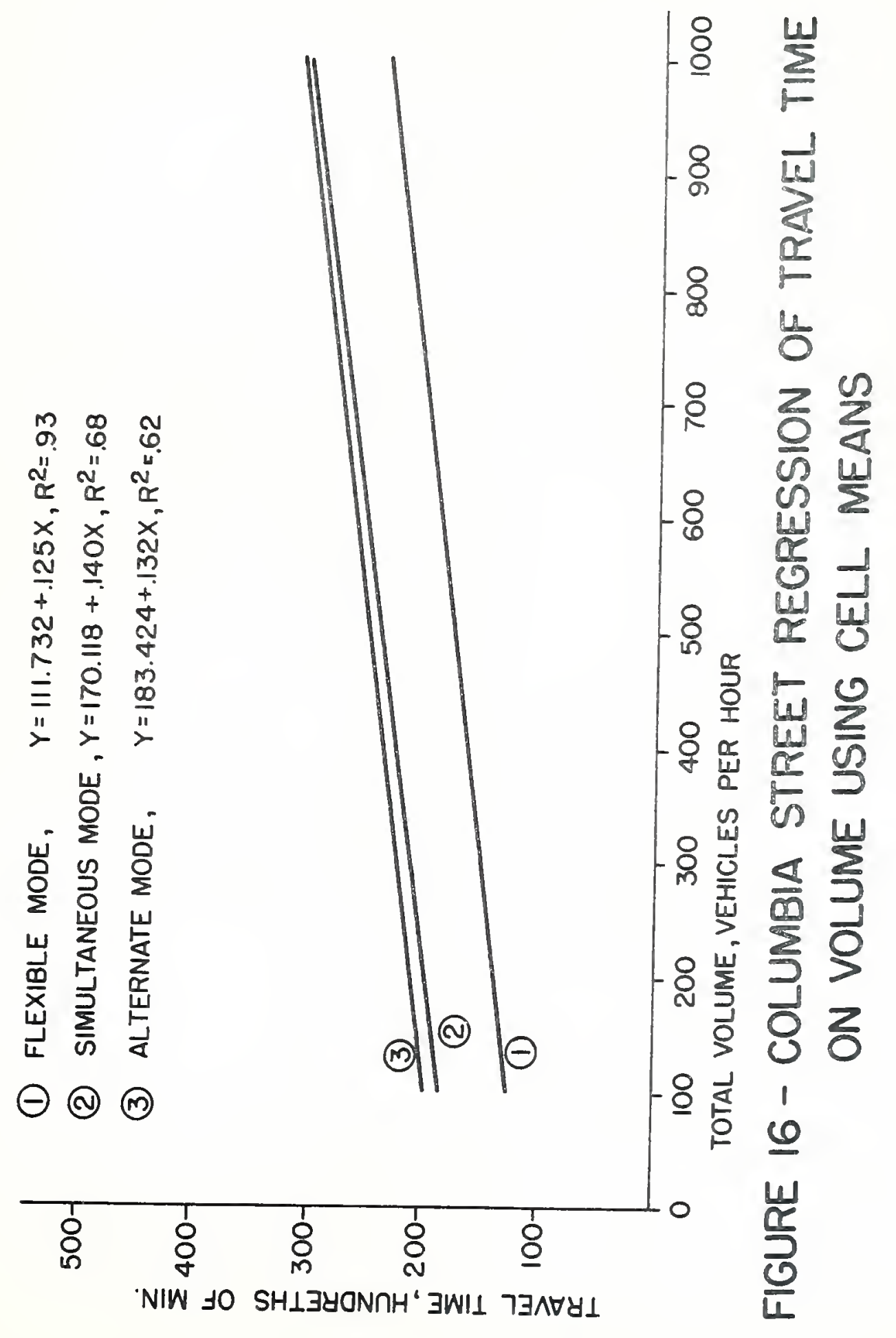




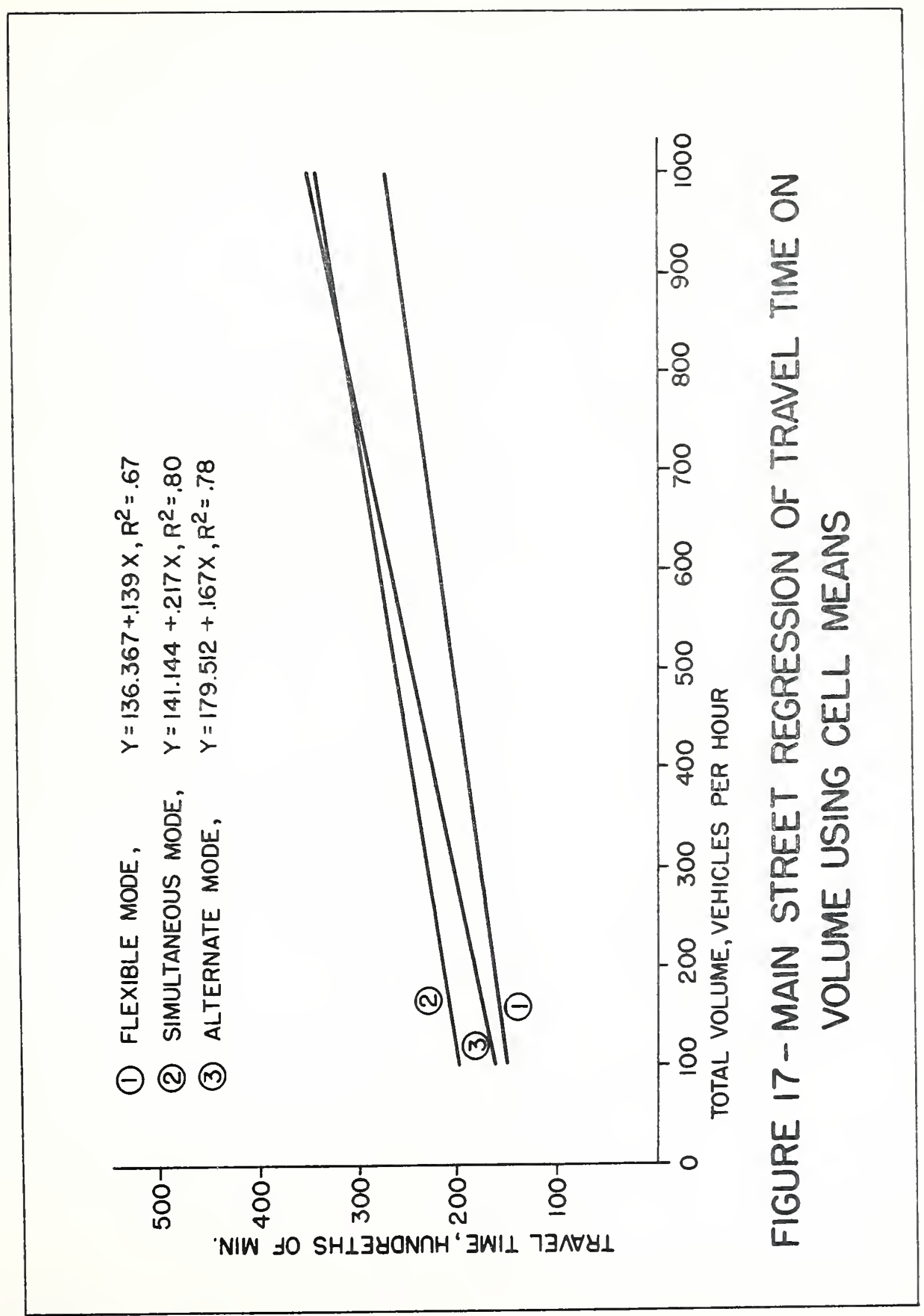


unequal cell sizes must be used to test the means. The method developed by Henry Scheffé (21) is well suited to this problem. The hypothesis, $H_{0}: \bar{Y}_{i}=\bar{Y}_{j}$, is tested, and $\bar{Y}_{i}$ and $\bar{Y}_{j}$ are declared significantly different at level $\alpha$ if:

$$
\left|\bar{Y}_{i}-\bar{Y}_{j}\right|>\sqrt{(K-1) F_{\alpha}} \sqrt{s^{2}\left(\frac{1}{n_{i}}+\frac{1}{n_{j}}\right)}
$$

where $\bar{Y}_{i}$ and $\bar{Y}_{j}$ are the means being tested, $K$ is the total number of means among which constrasts are being made, $\mathrm{n}_{i}$ and $\mathrm{n}_{j}$ are the numbers of observations upon which $\bar{Y}_{i}$ and $\bar{Y}_{j}$ are based, $s^{2}$ is the unbiased estimate of the error variance (error MS with df degrees of freedom in this case), and $\mathrm{F}_{\alpha}$ is the $100 \alpha$ percent point from the $\mathrm{F}$-distribution with $\mathrm{K}-1$ and df degrees of freedom. All pairs of means for the independent variables (DT, RT, and S) were tested by this method. This procedure showed the flexible means for each variable to be significantly lower than the alternate and simultaneous means at the level $\alpha=0.05$ in every case (Table 9)。

\section{Economic Analysis}

The initial step of the economic analysis is identification of the costs involved. Here the concern is the total cost of making a run through the signal system, so that a comparison of the costs for the different modes of operation may be obtained.

The operation of a vehicle incurs two basic costs, these being the cost of operating the vehicle and the value placed upon the motorist's time consumed while operating the vehicle. The operating cost of the vehicle can be further divided into fixed and variable costs. Fixed costs remain constant whether the vehicle is used or left idle; examples 
Table 9. Results of Scheffé Test for Differences in Means ${ }^{a}$.

\begin{tabular}{|c|c|c|c|c|c|}
\hline Street & Variable & $\begin{array}{c}\text { Hypothesis } \\
\text { Tested }\end{array}$ & $\begin{array}{c}\text { Difference } \\
\text { in Means }\end{array}$ & $\begin{array}{l}\text { Test Value } \\
\text { a } \alpha=0.05\end{array}$ & Result $t^{b}$ \\
\hline \multirow[t]{2}{*}{ COLUMBIA } & \multirow{3}{*}{$\begin{array}{l}\text { Delay Time } \\
\mathrm{s}^{2}=1121.84\end{array}$} & $\overline{\mathrm{Y}}_{\mathrm{A}}=\overline{\mathrm{Y}}_{\mathrm{S}}$ & 3.52 & 8.20 & I \\
\hline & & $\bar{Y}_{S}=\bar{Y}_{F}$ & 65.07 & 8.11 & S \\
\hline \multirow{4}{*}{$\begin{array}{l}n_{S}=63 \\
n_{A}=37 \\
n_{F}=64\end{array}$} & & $\overline{\mathrm{Y}}_{\mathrm{A}}=\overline{\mathrm{Y}}_{\mathrm{F}}$ & 61.55 & 7.27 & $S$ \\
\hline & & & & & \\
\hline & \multirow{3}{*}{$\begin{array}{l}\text { Running Time } \\
s^{2}=361.64\end{array}$} & $\bar{Y}_{A}=\bar{Y}_{S}$ & 6.73 & 4.66 & S \\
\hline & & & 7.04 & 4.57 & $\mathrm{~S}$ \\
\hline \multirow[t]{4}{*}{$\mathrm{df}=146$} & & $\overline{\mathrm{Y}}_{\mathrm{A}}=\overline{\mathrm{Y}}_{\mathrm{F}}$ & 14.77 & 4.13 & S \\
\hline & \multirow{3}{*}{$\begin{array}{l}\text { Stops } \\
s^{2}=1.04\end{array}$} & $\overline{\mathrm{Y}}_{\mathrm{A}}=\overline{\mathrm{Y}}_{\mathrm{S}}$ & 0.73 & 0.25 & S \\
\hline & & $\bar{Y}_{S}=\bar{Y}_{F}$ & 1.19 & 0.25 & S \\
\hline & & $\bar{Y}_{A}=\bar{Y}_{F}$ & 1.92 & 0.22 & S \\
\hline
\end{tabular}

\begin{tabular}{|c|c|c|c|c|c|}
\hline \multirow[t]{2}{*}{ MAIN } & \multirow{3}{*}{$\begin{array}{l}\text { Delay Time } \\
s^{2}=1998.06\end{array}$} & $\overline{\mathrm{Y}}_{\mathrm{A}}=\overline{\mathrm{Y}}_{\mathrm{S}}$ & 5.75 & 10.77 & I \\
\hline & & $\bar{Y}_{S}=\bar{Y}_{F}$ & 30.07 & 7.78 & $\mathrm{~S}$ \\
\hline $\begin{array}{l}\mathrm{n}_{\mathrm{S}}=63 \\
\mathrm{n}_{\mathrm{A}}=39\end{array}$ & & $\overline{\mathrm{Y}}_{\mathrm{A}}=\overline{\mathrm{Y}}_{\mathrm{F}}$ & 35.82 & 10.89 & $\mathrm{~S}$ \\
\hline$n_{F}^{A}=61$ & \multirow{3}{*}{$\begin{array}{l}\text { Running Time } \\
\mathrm{s}^{2}=659.10\end{array}$} & $\overline{\mathrm{Y}}_{\mathrm{A}}=\overline{\mathrm{Y}}_{\mathrm{S}}$ & 2.85 & 6.19 & $I$ \\
\hline & & $\overline{\mathrm{Y}}_{\mathrm{S}}=\overline{\mathrm{Y}}_{\mathrm{F}}$ & 28.44 & 5.62 & S \\
\hline \multirow{4}{*}{$\mathrm{d} f=145$} & & $\bar{Y}_{A}=\bar{Y}_{F}$ & 25.59 & 6.26 & $S$ \\
\hline & \multirow{3}{*}{$\begin{array}{l}\text { Stops } \\
s^{2}=1.01\end{array}$} & $\bar{Y}_{A}=\bar{Y}_{S}$ & 0.43 & 0.25 & $S$ \\
\hline & & $\bar{Y}_{S}=\bar{Y}_{F}$ & 1.41 & 0.22 & $\mathrm{~S}$ \\
\hline & & $\bar{Y}_{A}=\bar{Y}_{F}$ & 1.84 & 0.25 & S \\
\hline
\end{tabular}

a Subscript code: S, simultaneous mode; A, alternate mode; F, flexible mode.

$\mathrm{b}_{\mathrm{I}}$, insignificant differences in means; $S$, significant differences in means. 
are depreciation and insurance. Variable costs include expenses for gasoline, tires, and motor oil. These costs are dependent upon the amount of vehicle use, speed of travel, type of road surface, and other factors.

It is apparent that the total vehicle cost for making a run through the signal system consists of the cost of operating a vehicle at a given speed, the additional cost incurred by making stops, the added cost of delays, and the value placed upon the motorist's time.

Since the variables in the statistical analysis were shown to have insignificant interaction terms, and the Scheffé test shows significant differences in the means, the grand mean for each variable for the different modes was used to develop an economic equation for computing the cost per run for the different signal modes and travel time routes (Table 10). Using the independent variables $R T$, DT, and $S$ the following equation was developed:

$$
C R_{i j}=R T_{i j}\left(A_{1}+A_{4}\right)+D T_{i j}\left(A_{2}+A_{4}\right)+S_{i j}\left(A_{3}\right)
$$

where:

$$
\begin{aligned}
& \begin{array}{l}
\mathrm{CR}_{i j} \text { Total cost to motorist per run through } \\
\text { signal system on route } i \text { and mode } j \text {. }
\end{array} \\
& \begin{array}{l}
\mathrm{RT}_{i j} \text { Average running time per run required for } \\
\text { route } i \text { and mode } j \text {. }
\end{array} \\
& \begin{array}{l}
\mathrm{DT}_{i j} \text { Average delay time experienced for route } \\
i \text { and mode } j \text {. }
\end{array} \\
& S_{i j} \text { Average number of stops made per run for } \\
& \text { route } i \text { and mode } j \text {. } \\
& \text { A } 1 \text { Operating cost for standard vehicle running } \\
& \text { on high type pavement at } 20 \mathrm{mph} \text {. } \\
& A_{2} \text { Idling cost of standard vehicle during delay. }
\end{aligned}
$$


Table 10. Over-All Means Obtained from the Statistical Analysis ${ }^{a}$

MAIN STREET

\begin{tabular}{lccc}
\hline Signal Mode & Delay Time & Running Time & Stops Per Run \\
\hline Simultaneous & 90.79 & 205.75 & 2.95 \\
Alternate & 96.54 & 202.90 & 3.38 \\
Flexible & 60.72 & 177.31 & 1.54 \\
Standard Error & 44.60 & 25.60 & 1.02 \\
\hline
\end{tabular}

COLUMBIA STREET

\begin{tabular}{lccc}
\hline Signal Mode & Delay Time & Running Time & Stops Per Run \\
\hline Simultaneous & 82.93 & 175.46 & 2.38 \\
Alternate & 79.41 & 182.19 & 3.11 \\
Flexible & 17.86 & 168.42 & 1.19 \\
Standard Error & 33.40 & 19.00 & 1.00 \\
\hline
\end{tabular}

a The units applicable to table values are one hundreths of a minute; to obtain time in seconds these values must be multiplied by 0.60 . Stops per run have the appropriate units as written. 


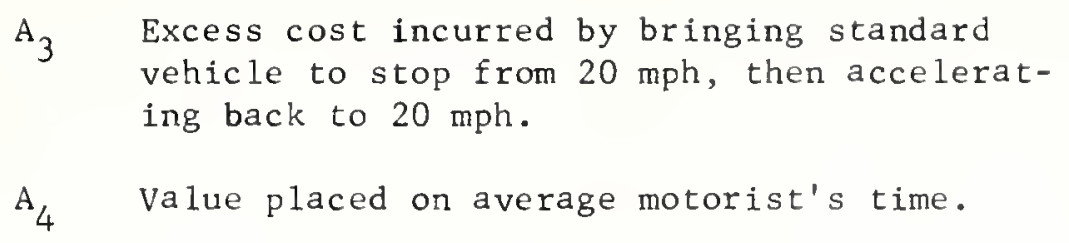

By checking spot speeds within the system, the average running speed was found to be approximately 20 miles per hour, therefore, this speed was used for determining operating costs. Values determined by Winfrey (22) were used for the constants $A_{1}, A_{2}$, and $A_{3}$. Winfrey bases these costs upon an average vehicle that most closely represents the entire range of vehicles using the street system. This vehicle is thought to be representative of the range of passenger cars in use today. It is a 3,500 pound passenger car with a gross running weight of 4,000 pounds and is equipped with an eight cylinder engine of 302 cubic inches. $\mathrm{A}_{1}$ is the cost of operating this vehicle at 20 miles per hour on a level tangent section of a high type pavement. Included in this constant are costs for tires, oil, maintenance, depreciation, and gasoline (including taxes). $A_{2}$ is the cost of idling the standard vehicle during delays, and includes gasoline, oil, engine maintenance and depreciation costs. The excess cost incurred by bringing this vehicle to a stop from 20 miles per hour, and then accelerating back to $20 \mathrm{miles}$ per hour is represented by $A_{3}$. The value to be placed upon a motorist's time is a much debated item; however, a figure in common use today is 1.60 dollars per hour. This figure was used for $\mathrm{A}_{4}{ }^{\circ}$ Table 11 is a summary of the costs used in the analysis.

Substitution of the appropriate values into the economic equation yielded the cost per run for the different signal modes and travel time routes. This cost was then expanded in each case to an annual cost by 
Table 11. Values Used to Compute Operating and Delay Costs

Vehicle: $4000 \mathrm{lb}$ passenger car Roadway Surface: High type pavement in good condition

Dollars Running Cost at Uniform Speed on Level Tangents ${ }^{a}$

\begin{tabular}{|c|c|c|c|c|c|c|}
\hline \multirow{2}{*}{$\begin{array}{l}\text { Speed } \\
\text { mph }\end{array}$} & \multicolumn{5}{|c|}{ Running Cost by Item } & \multirow{2}{*}{$\begin{array}{l}\text { Tota } 1 \\
\text { Cost }\end{array}$} \\
\hline & Fue $1^{b}$ & Tires & $\begin{array}{c}\text { Engine } \\
\text { Oil }\end{array}$ & $\begin{array}{c}\text { Mainten- } \\
\text { ance }\end{array}$ & $\begin{array}{c}\text { Deprecia- } \\
\text { tion }\end{array}$ & \\
\hline 20 & 16.07 & 0.82 & 1.75 & 5.93 & 18.03 & 42.60 \\
\hline
\end{tabular}

Cost of Idling Engine with Stationary Vehicle ${ }^{c}$

Idling Cost by Item

Total

\begin{tabular}{ccccc}
\hline Fue 1 & $\begin{array}{c}\text { Engine } \\
\text { Oil }\end{array}$ & $\begin{array}{c}\text { Engine } \\
\text { Maintenance }\end{array}$ & $\begin{array}{c}\text { Deprecia- } \\
\text { tion }\end{array}$ & $\begin{array}{c}\text { Cost } \\
84.64\end{array}$ \\
\hline
\end{tabular}

Dollars Excess Cost of Speed-Change Cycles Excess Cost about Continuing at Initial Speed

\begin{tabular}{ccccc} 
Initial & \multicolumn{3}{l}{ Speed Reduced to and Returned from, mph } \\
\cline { 2 - 5 } & Stop & 5 & 10 & 20 \\
\hline 20 & 4.95 & 3.81 & 2.66 & 1.44 \\
\hline
\end{tabular}

$\frac{\text { Cost of Motorist's Time }}{1.60}$

bunit: dollars per 1000 vehicle miles.

Includes state and federal tax of 12 cents per gallon.

dunit: dollars per 1000 vehicle hours.

Unit: dollars per 1000 speed change cycles.

Unit: dollars per hour.

Source: Reference 22 . 
applying the associated yearly volumes for the years 1963 through 1970. Average volumes were known for the years of 1963 and 1970 . In order to obtain volumes for the intervening years a linear growth was assumed, with no attempt being made to determine a growth rate factor since the time period was short and the growth was relatively smal1 (Table 12). The results of these calculations shown in Table 13 show the flexible mode produces significantly lower costs to the road-user than the simultaneous or alternate modes. The simultaneous mode is also shown to be an improvement over the alternate mode. Therefore, in order to be conservative the economic evaluation was done relative to the simultaneous system. See APPENDIX A for sample calculations.

The money invested in the installation of the flexible system (approximately 200,000 dollars) could conceivably have been invested in business or deposited in savings; in both cases a profit in the form of interest paid on the investment would have most likely resulted. Therefore, each year's savings cannot be used for analytical purposes until an appropriate interest rate has been applied, and the worth of each year's saving is established for the base year of 1963. Here, in order to be conservative and to compensate for the effects of inflation an interest rate of ten percent was used. This procedure reveals the flexible system to have realized benefits in terms of operating and delay costs valued at approximately 790,000 dollars over the simultaneous system during the years it has been in operation (Table 14). 


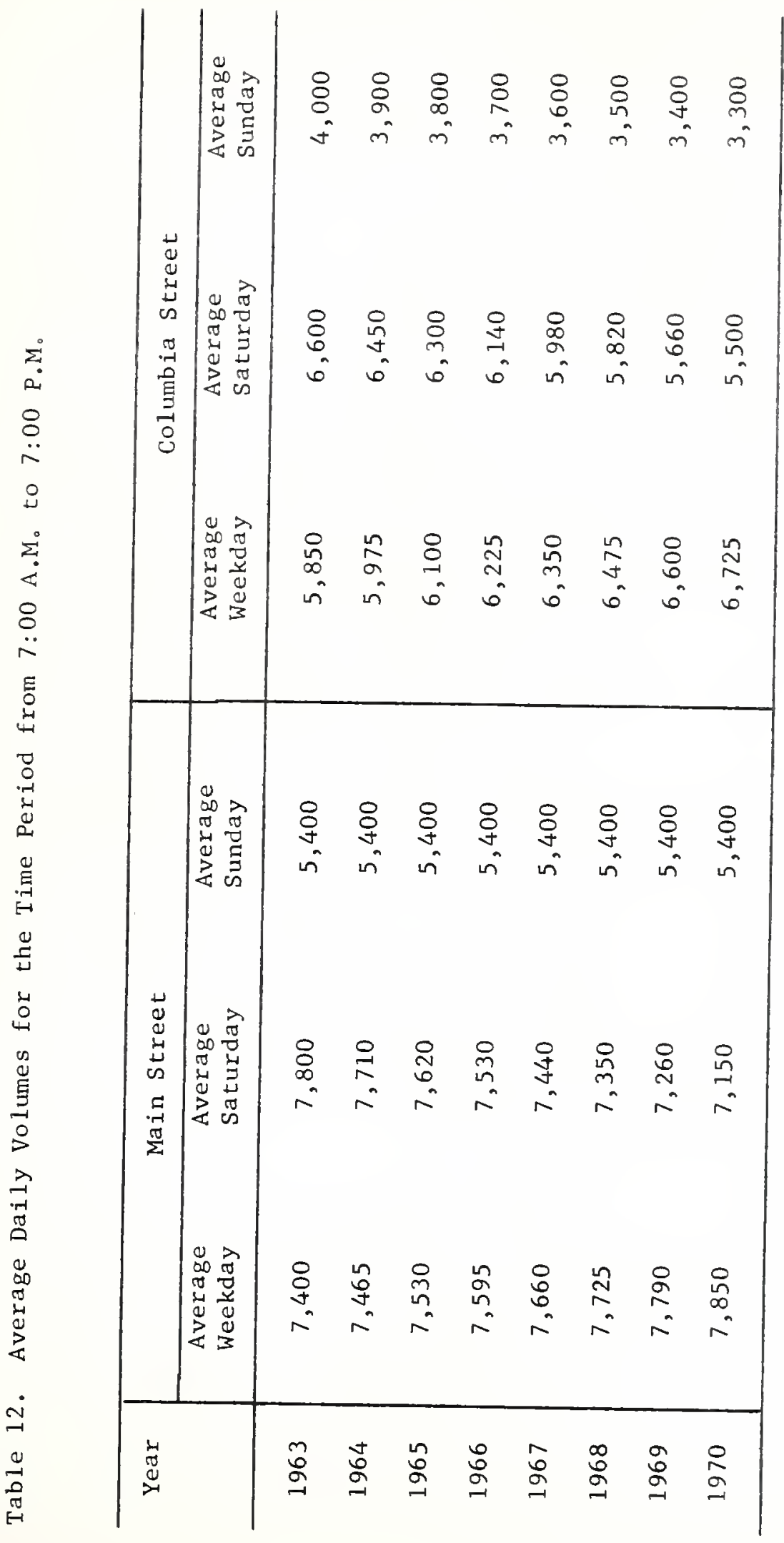


Table 13. Annual Cost to Users for Different Signal Systems ${ }^{2}$

\begin{tabular}{|c|c|c|c|c|}
\hline \multirow{2}{*}{ Year } & \multirow[t]{2}{*}{ Street } & \multicolumn{3}{|c|}{ Modes of Operation } \\
\hline & & Simultaneous & Alternate & Flexible \\
\hline \multirow[t]{3}{*}{1963} & Main & 325,520 & 332,040 & 254,280 \\
\hline & Columbia & 225,790 & 233,140 & 165,380 \\
\hline & Tota 1 & 551,310 & 565,180 & 419,660 \\
\hline \multirow[t]{3}{*}{1964} & Main & 327,050 & 333,600 & 255,470 \\
\hline & Columbia & 227,910 & 235,340 & 166,940 \\
\hline & Tota 1 & 554,960 & 568,940 & 422,410 \\
\hline \multirow[t]{3}{*}{1965} & Main & 328,560 & 335,150 & 256,660 \\
\hline & Columbia & 230,040 & 237,530 & 168,500 \\
\hline & Total & 558,600 & 572,680 & 425,160 \\
\hline \multirow[t]{3}{*}{1966} & Ma in & 330,090 & 336,710 & 257,850 \\
\hline & Columbia & 232,110 & 239,670 & 170,000 \\
\hline & Tota 1 & 562,200 & 576,380 & 427,850 \\
\hline \multirow[t]{3}{*}{1967} & Main & 331,610 & 338,260 & 259,050 \\
\hline & Columbia & 234,170 & 241,800 & 171,520 \\
\hline & Tota 1 & 565,780 & 580,060 & 430,570 \\
\hline \multirow[t]{3}{*}{1968} & Main & 333,140 & 339,810 & 260,230 \\
\hline & Columbia & 236,240 & 243,940 & 173,040 \\
\hline & Tota 1 & 569,380 & 583,750 & 433,270 \\
\hline \multirow[t]{3}{*}{1969} & Main & 334,660 & 341,370 & 261,420 \\
\hline & Columbia & 238,310 & 246,070 & 174,550 \\
\hline & Tota 1 & 572,970 & 587,440 & 435,970 \\
\hline \multirow[t]{3}{*}{1970} & Main & 335,890 & 342,630 & 262,390 \\
\hline & Columbia & 240,380 & 248,210 & 176,070 \\
\hline & Total & 576,270 & 590,840 & 438,460 \\
\hline
\end{tabular}




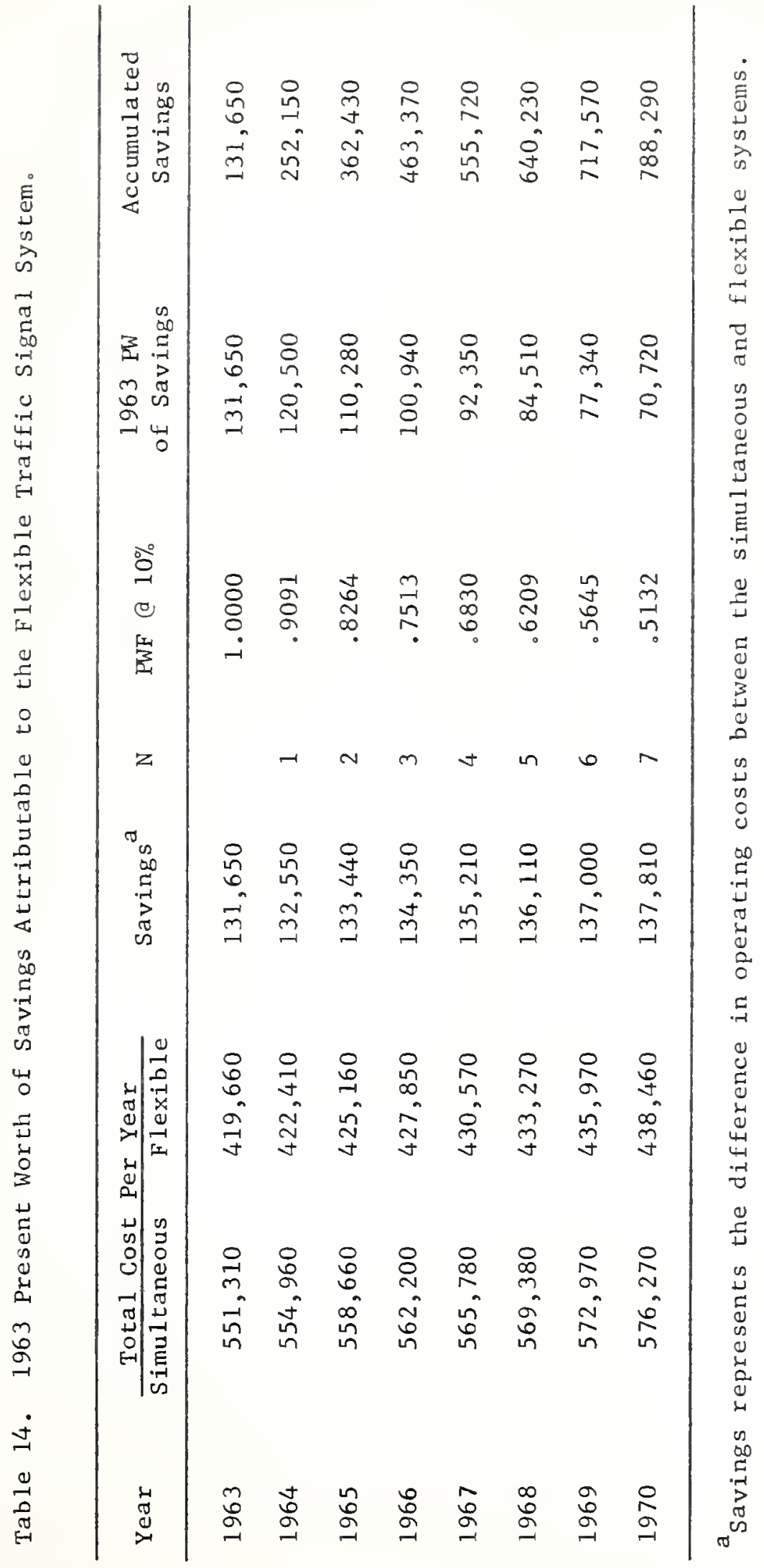




\section{RESULTS AND CONCLUSIONS}

The results of the economic analysis show quite vividly that the flexible coordinated traffic signal system was a good investment for the City of Lafayette. The analysis of the data would possibly have been more meaningful if the random mode of operation had been allowed to remain in the analysis, since this was the basic condition. A comparison to this mode would have revealed the actual amount saved by the new system over the previous installation. This would have been desirable but was not possible due to the distribution of the random data. Conceivably the random system could have been brought up to the performance standards of the simultaneous system, however, the random system was not coordinated and would have required constant monitoring and maintenance to keep the timing of adjacent signals synchronized. Therefore the simultaneous system's performance can be thought of as being the ultimate that could have been obtained with no capital expenditure. This makes the result of the analysis more meaningful and shows again the initial investment has proven to be very sound indeed. Although a statistical analysis could not be performed using the random data, a look at the means of the variables for this mode reveals that this system probably operated at a higher cost to the user than the simultaneous system, therefore, greater savings would have been realized over the basic condition than those reported. This could be expected from the very nature of the random mode of 
operation, in that it does not seek to set up an orderly flow of traffic. It must be remembered that this is not the result of sound statistical procedure, and is not conclusive evidence that the simultaneous system is actually better than the random system, but it does seemingly reinforce the conclusions reached by this research.

Since a check of the effect of the various modes on cross traffic was not possible it must be assumed that cross traffic was not adversely affected by the operation of the flexible mode. This research reports only savings produced on Main and Columbia Streets, so if the flexible mode could do no better than produce results comparable to the simultaneous mode in the crossing direction the savings reported would remain valid. Investigation of travel time runs done in the crossing direction for the flexible mode reveals no serious problem. Also a check on the average running speed shows cross traffic has not suffered unduly from the flexible system (APPENDIX B). A comparison of the effect of the modes on cross traffic would undoubtedly reveal additional savings attributable to the flexible system.

A conservative approach has been taken in this research in order to avoid unfairly biasing the result in favor of the flexible signal system. When compared to its original cost the savings attributable to this system seem staggering; however, if the combined savings for the total system were known it would probably be much greater. Other factors that tend to make the analysis conservative are the ten percent interest rate used in the economic analysis, and the fact that only 12 hour volumes were used in calculating the costs. The number of vehicles per day using the system outside the study time were small in comparison to volumes used, but this would certainly have added to the savings. The following 
are the major findings of this research:

1. The flexible system is shown to be a significant improvement over the simultaneous coordinated and alternate coordinated systems for the full range of volumes (400-1100 veh/hr) tested. This system produces lower running times, delay times, and number of stops per run than either of the other systems under comparison.

2. At the present time the flexible system is saving approximately 140,000 dollars per year in delays and operating costs over the next best system. This figure will undoubtedly increase in the future since volumes are ever increasing.

3. The accumulated savings attributable to the flexible system for the period of time from 1963 through 1970 amounts to approximately 790,000 dollars. This is the 1963 present worth of the savings with a ten percent rate of return applied.

4. Based upon a installation cost of about 200,000 dollars the flexible system has realized a net savings of 590,000 dollars (1963-1971).

1963 present worth of savings at ten percent rate of return $\$ 790,000$

Cost of installation 200,000

Net savings attributable to the flexible system 
5. The flexible system effectively paid for itself in delay and operating cost savings in less than two years from its installation date (Figure 18). 


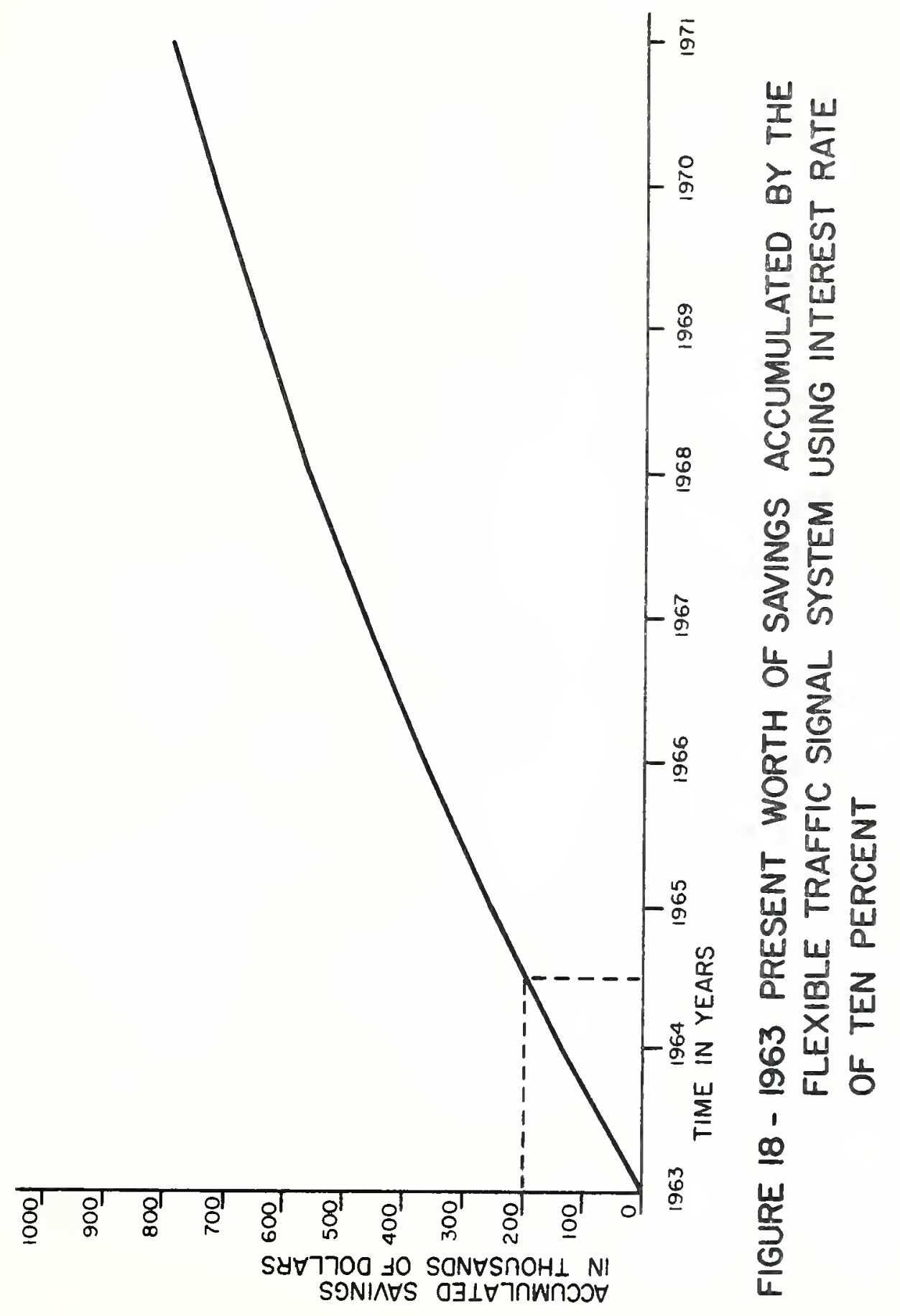




\section{SUGGESTIONS FOR IMPROVEMENT AND ADDITIONAL RESEARCH}

\section{Suggestions for Improving the Flexible system}

The original timing plan for the Lafayette signal system was developed in 1963 by the Traffic Control Corporation of Chicago, Illinois. This plan was formulated from a limited amount of data made available through earlier efforts of this research. The timing plan was meant to be a starting point for the development of the most efficient system for this particular city and equipment. As stated in the report made to the city by Traffic Control Corporation: "A copy of this traffic information, along with other reference material, is included for use in the further field work that must be done to realize the full efficiency of the signal system. The following suggestions should be considered as only a starting point from which a really efficient PR Traffic Signal system can be developed for the City of Lafayette" (23).

Many times officials of small cities have the tendency to leave well enough alone. This is caused by fear of criticism, lack of trained personnel, lack of funds, etc. With the insight provided by hindsight it can clearly be seen that this would have been the best philosophy in many cases when supposed "improvements" have provided undesirable results. This must not be used as an excuse for being satisfied with less than the optimum, for one should constantly strive to develop more efficient methods for the movement of persons and goods. 
The Lafayette signal system is now operating on much the same plan that was established in 1963. A few of the offsets have been speeded up in order to compensate for the short block lengths, but nothing has been done to compensate for increased traffic volumes or changes in traffic patterns. Stipulations might have been made in the original contract to have the Traffic Control Corporation periodically revise and update the signa 1 timing.

Presently this system offers great advantages over other systems, but its potential is not being fully realized under changing conditions. The following discussion and suggestions are based upon observations made during the data collection and the results of this research.

The detector located between Fifth and Sixth Streets on Main Street is placed to detect circulating traffic in the CBD. This is useful at times such as Friday evenings when businesses remain open until 9:00 P.M. At these times vehicles tend to accumulate within the bounds of the system with a lesser amount of traffic coming into and leaving the area. When this occurs the system would then be switched to the circulation detector for its operating information. This tends to keep the system operating on a longer cycle length in order to compensate for high volumes within the system. At the present time the equipment necessary for this phase of the operation is inoperative, and in fact, has been unused since its installation. If this equipment were programmed to operate in an efficient manner and were put into use it could be a valuable aid in moving traffic more efficiently at certain times in the Lafayette CBD.

As presently programmed the input volumes seldom reach a level high enough to switch the system into heavy offset operation. If this offset 
were utilized the system would switch to simultaneous operation at high volumes. From the motorist's viewpoint the simultaneous operation might be more acceptable and seem to produce lower travel times. As the system presently operates, high volumes produce queues of over one full block length and create extensive congestion at cross streets. This is, to a large degree, due to the extremely short block lengths. Simultaneous operation utilizing a very long cycle length could be effective in reducing the magnitude of this congestion.

The data for the flexible mode shows high numbers of stops of very short duration at various locations throughout the system. Seventy-five percent of the stops at these locations are six seconds or less in length with many of them only two to three seconds long. If at these intersections, the offsets could be altered sufficiently to eliminate these very short delays without adversely effecting the cross traffic, a savings in delay and operating cost to the motorist could be realized. Also if the delays caused by these stops were subtracted from the data previously analyzed, the result would have shown this system even more superior. Table 15 shows a summary of the stops made at locations where this has its most pronounced effect. This occurs exclusively in sections of very short block lengths, suggesting that signal timing has not been set to be fully compatible with blocks of such short lengths.

The intersection of Third and Ferry streets presents a problem similar to the previous one. This intersection is located at the end of a fairly long unsignalized section of roadway. The average driver has a tendency to beat the offset here again. The posted speed limit is higher than the speed of progression so most drivers arrive at Third and Ferry Streets 
Table 15. Stop Sumarization for Locations with High Incidence of Short Term Delays for Flexible Mode of Operation.

Duration of Stop in Seconds

\begin{tabular}{|c|c|c|c|c|c|c|c|c|}
\hline \multirow{2}{*}{ Location } & \\
\hline & $0-6$ & $7-12$ & $13-18$ & $19-24$ & $25-30$ & $31-36$ & $37-42$ & $43-48$ \\
\hline \multicolumn{9}{|l|}{ Columbia } \\
\hline Second & 15 & 3 & & & & & & \\
\hline Third & 2 & & & - & & & & \\
\hline Fourth & 13 & 1 & & & & & 2 & 1 \\
\hline \multicolumn{9}{|l|}{ Main } \\
\hline Second & 4 & 1 & & & & 1 & 1 & 1 \\
\hline Third & 12 & 3 & 1 & & 1 & 1 & & 1 \\
\hline Fourth & 6 & 1 & & & & & 1 & \\
\hline \multicolumn{9}{|l|}{ Third } \\
\hline Ferry & 5 & 26 & 11 & 3 & 1 & & & \\
\hline Main & 15 & 6 & 1 & & & & & 1 \\
\hline \multicolumn{9}{|l|}{ Fourth } \\
\hline Main & 15 & 1 & & & & & & \\
\hline Brown & 15 & 7 & & & & & & \\
\hline
\end{tabular}


6-12 seconds ahead of the green light. A total of 64 runs was made through this intersection and of these 64 runs a stop was required 46 times. Here again the need to re-evaluate the offset plan is seen. other locations suffer this same malady but not as severely as the Third and Ferry location.

The original signal timing was based upon 1963 volumes; however, during the period of time that has elapsed since then traffic volumes have grown and patterns have changed. There has been a ten percent increase in volumes in the east-west direction but a much larger increase has occurred in the north-south direction (around 20 percent). This shows a definite change in traffic patterns. These factors indicate that the original timing should be re-evaluated and updated to meet the present needs more effectively.

In general motorists tend to drive faster than the speed of progression when given the opportunity. In some cases this is due to extremely low speeds of progression, but usually results from the motorists' desire "to get there faster". Most motorists do not realize they will only suffer more delay by driving at higher rates of speed. The majority of drivers does not know that the signal timing is designed to operate at peak efficiency at a certain speed. It seems if the public were periodically given information about progression speeds and the basic operational principles of the system, they would utilize the system more effectively. It is only logical that the motorist will not realize the full benefit obtainable from the system if he doesn't know what it can do for him.

The location and utilization of the detection units should be checked to determine whether or not they are providing realistic information to 
the computer. It is imperative that this phase of the operation transmit an accurate picture of actual traffic conditions, because the operating plan for the entire system is based upon the detector input. At present detection is thought to be insufficient. Three detectors monitor inbound traffic and two monitor outbound traffic, however, the system is capable of handling four inputs for each direction. An increase in detection would seemingly transmit a more accurate picture of actual conditions. Also in a grid street system such as this it would seem more logical to base detection on east-west and north-south movements rather than inbound and outbound movements.

As previously stated the preceding statements are only suggestions based mostly upon observations made during data collection. Any actual improvements made would most certainly have to be based upon factual information obtained from detailed studies of volumes and traffic patterns and eventual testing of the proposed improvements on the system.

\section{Suggestions for Additiona1 Research}

As the Lafayette signal system presently operates, it has been shown to be far superior to less costly and less sophisticated systems. The flexibility of this system affords great savings in time and operating expenditures to the motorist. This is not to imply that the flexible system is the answer for all cities of comparable size. Additional research is needed in several areas. The following further research is recommended:

1. The flexible progressive system was compared to a coordinated alternate system and a coordinated simultaneous system. It would be of interest to compare the flexible progressive system to a simple 
progressive system since the operating characteristics of this system are more akin to the flexible system.

2. This research was done comparing only delay costs and operating costs. It would also be desirable to determine the effects of maintenance costs upon the results.

3. The development of a better method for determining volumes experienced by the test vehicle is desirable. Many times average volumes do not reflect the true nature of the volume conditions in the immediate area of the test vehicle.

4. It is also suggested that the present system be improved through information made available by this research and other sources. Then a comparison should be made between the present system and the improved system, and the effects of improvements made for east-west movement on the traffic flow in the north-south direction should be tested. 
BIBLIOGRA PHY 
BIBLIOGRA PHY

1. Determining Travel Time, Procedure Manual 3B, National Committee on Urban Transportation, 1958.

2. Haley, Charles E., Edward M。 Hall, and Arnold A. Johnson, "Travel Time - A Measure of Service and A Criterion for Improvement Priorities", Highway Research Record №. 35, Highway Research Board, Washington, D. C.,

3. Cribbins, P. D., J.W. Horn, and C. E. Vick, "Development and Use of Maximum-Car Techniques for Measuring Travel Time", Bulletin 303, Highway Research Board, Washington, D. C., 1961 .

4. Walker, W. Po, "Speed and Travel Time in Urban Areas", Bulletin 156, Highway Research Board, Washington, D. C., 1957.

5. Berry, D.S., "Evaluation of Techniques for Determining Over-all Travel Time", Proceedings, 31st Annual Meeting, Highway Research Board, Washington, D. C., $1 \overline{952 .}$

6. Treadway, T. B., "An Analys is of Travel Speed and Delay on a HighVolume Highway", Joint Highway Research Project No. 10, Purdue University, June, 1965 。

7. Baldock, R. H., "The Annual Cost of Highways", Highway Research Record No. 12, Highway Research Board, Washington, D. C., 1963.

8. Johnson, William F., "Use of Traffic Volume Data in Evaluation of Highway User Costs of the Economic Analysis", Highway Research Record No. 100, Highway Research Board, Washington, D. C., 1965.

9. Winfrey, Robley, "Research on Motor Vehicle Performance Related to Analyses for Transportation Economy", Highway Research Record. No. 77, Highway Research Board, Washington, D. C., 1965.

10. Torres, J. F., "The Effects of Street Geometrics and Signalization on Travel Time and Their Relationships to Traffic Operations Evaluation", Highway Research Record No. 211, Highway Research Board, Washington, D。C., 1967 。

11. Bierley, Robert L. and Jon Parkinson, "The Pacer System", Highway Research Record №. 49, Highway Research Board, Washington, D. C。, 1964。 
12. Bisse11, Howard H., "Analys is of a Three-Street Traffic System",

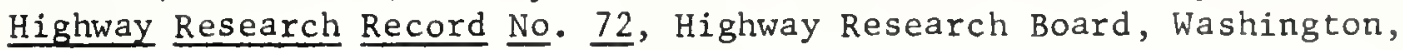
D.C., 1965 .

13. Kay, J. L., "Signal System Studies: A New Approach", Traffic Engineering, Institute of Traffic Engineers, Washington, D. C., Vol. 40, No. 4, January, 1970.

14. Bleyl, Robert L., "A Practical Computer Program for Designing Traffic-Signal-System Timing Plans", Highway Research Record No. 211, Highway Research Board, Washington, D. C., 1967.

15. Miller, Stephen B., and John D. C. Little, "Evaluation and Improvement of Traffic Signal Settings by Simulation", Highway Research Record No. 170, Highway Research Board, Washington, D. C., 1967 .

16. Electro-Matic PR Coordinated Traffic Signal Control Systems, Laboratory for Electronics, Inc., Norwa1k, Conn., 1965.

17. Dixon, W. J., and F。 J. Massey, Jr., Introduction to Statistical Analysis, McGraw-Hill Book Co。, New York, 1969.

18. "Data Summarization with Homogeneity Tests", Datasum, Statistical Laboratory Library Program, Purdue University.

19. Box, G。E. P., "Some Theorems on Quadratic Forms applied in the Study of Analysis of Variance Problems", Annals of Mathematical Statistics, June, 1954 .

20. "Two-Way Unequal Ce11-Size Analysis of Variance", Statistical Laboratory Library Program, Purdue University.

21. Scheffé, H., "A Method for Judging All Contrasts in the Analys is of Variance", Biometrika, Vol. 40, Parts 1 and 2, June, 1958.

22. Winfrey, R., Economic Analysis for Highways, International Textbook Co., Scranton, Pennsylvania, 1969.

23. "Suggested Timing Program City of Lafayette, Indiana, PR Signal System", Traffic Control Corporation, Chicago, Illinois. 
APPENDICES 
APPENDIX A

Sample Calculations for the Annual Operating and Delay

Costs to the Road-Users for a Given Route and Mode of Operation

$$
C R_{i j}=R T_{i j}\left(A_{1}+A_{4}\right)+D T_{i j}\left(A_{2}+A_{4}\right)+S_{i j}\left(A_{3}\right)
$$

given:

$$
\begin{aligned}
& \text { i, Columbia Street } \\
& \text { j, Simultaneous Mode }
\end{aligned}
$$

from Table 10

$\underline{\text { from Table } 11}$

$$
\begin{array}{ll}
\mathrm{RT}=175.46 & \mathrm{~A}_{1}=42.60 \$ / 1000 \text { veh miles } \\
\mathrm{DT}=82.93 & \mathrm{~A}_{2}=114.86 \$ / 1000 \text { veh hrs } \\
\mathrm{S}=2.38 & \mathrm{~A}_{3}=4.95 \$ / 1000 \text { stops } \\
\mathrm{A}_{4}=1.60 \$ / \mathrm{hr}
\end{array}
$$

Times recorded by the travel time and distance recorder are in hundreths of a minute; therefore, RT and DT must be multiplied by 0.60 to obtain time in seconds. Factors $A_{1}, A_{2}$ and $A_{4}$ must also be converted to dollars per second so the result of the economic equation has the appropriate units of dollars per vehicle run.

$$
\begin{aligned}
& \mathrm{RT}=0.60 \times 175.46=105.28 \mathrm{sec} / \text { veh run } \\
& \mathrm{DT}=0.60 \times 82.93=49.76 \mathrm{sec} / \text { veh run } \\
& \mathrm{S}=2.38 \text { stops/veh run }
\end{aligned}
$$




$$
\begin{aligned}
A_{1} & =42.60 \$ / 1000 \text { veh miles } \times \frac{1 \text { veh }}{1000} \times 20 \mathrm{mph} \times \frac{1 \mathrm{hr}}{3600 \mathrm{sec}} \\
& =.000237 \$ / \mathrm{sec}
\end{aligned}
$$

$A_{2}=114.86 \$ / 1000$ veh hrs $\times \frac{1 \text { veh }}{1000} \times \frac{1 \mathrm{hr}}{3600 \mathrm{sec}}$

$$
=.000032 \$ / \mathrm{sec}
$$

$A_{3}=4.95 \$ / 1000$ stops $X \frac{1}{1000}=.00495 \$ /$ stop

$\mathrm{A}_{4}=1.60 \$ / \mathrm{hr} \times \frac{1 \mathrm{hr}}{3600 \mathrm{sec}}=.000444 \$ / \mathrm{sec}$

$A_{1}+A_{4}=.000237+.000444=.000681 \$ / \mathrm{sec}$

$$
A_{2}+A_{4}=.000032+.000444=.000476 \$ / \mathrm{sec}
$$

$$
\begin{aligned}
C_{i j}= & 105.28 \mathrm{sec} / \text { veh run } X .000681 \$ / \mathrm{sec}+49.76 \mathrm{sec} / \mathrm{veh} \mathrm{run} \\
& X .000476 \$ / \mathrm{sec}+2.38 \mathrm{stops} / \text { veh run } \mathrm{X} .00495 \$ / \mathrm{stop} \\
= & .07169+.02548+.01178 \\
= & .10896 \$ / \text { veh run }
\end{aligned}
$$

This number is then expanded to the 1970 cost by applying the 1970 volume for Columbia street found in Table 12 .

$$
\begin{aligned}
& \text { Average Weekday }-6725 \mathrm{veh} / \text { day } \\
& \text { Average Saturday - } 5500 \mathrm{veh} / \mathrm{day} \\
& \text { Average Sunday - } 3300 \mathrm{veh} / \mathrm{day}
\end{aligned}
$$

Here each vehicle is assumed to traverse the entire length of the route; therefore, each vehicle represents one vehicle run so the units for the volumes become veh run/day. 
Cost for $1970=260$ weekdays/year X 6725 veh $\mathrm{run} /$ day $\mathrm{X} .10896$ \$/veh run

+ 52 Saturdays/year X 5500 veh run/day X .10896 \$/veh run

+52 Sundays/year X 3300 veh run/day X .10896 \$/veh run

$=190,516+31,163+18,698$

$=240,377 \$ /$ year

The results of these calculations are shown in Table 13. 
APPENDIX B

Table 16. Average Running Speeds for Different Modes and Routes ${ }^{a}$

\begin{tabular}{lccc}
\hline \multirow{2}{*}{ Street } & \multicolumn{3}{c}{ Mode } \\
\cline { 2 - 4 } & Alternate & Simultaneous & Flexible \\
\hline Main & 15.0 & 14.8 & 17.2 \\
Columbia & 16.4 & 17.2 & 17.9 \\
Third & - & - & 15.7 \\
Fourth & - & - & 17.0 \\
\hline
\end{tabular}

${ }^{\mathrm{a}}$ speeds in $\mathrm{mph}$.

Note: Speeds were obtained by dividing the route length by the average running time for that route. 

